\title{
Electrodynamics in the duskside inner magnetosphere and plasmasphere during a super magnetic storm on March 13-15, 1989
}

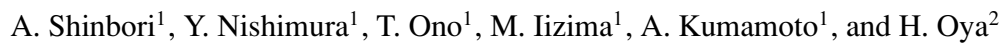 \\ ${ }^{1}$ Geophysical Institute, Tohoku University, Sendai 980-8578, Japan \\ ${ }^{2}$ Fukui University of Technology, Fukui 910-8505, Japan
}

(Received January 6, 2005; Revised June 5, 2005; Accepted June 7, 2005)

\begin{abstract}
Variations of cold plasma density distribution and large-scale electric field in the inner magnetosphere and plasmasphere during a geomagnetic storm were investigated by using the observation data of the Akebono satellite which has been carried out for more than 15 yeas since March, 1989. We focus on the super geomagnetic storm on March 13-15, 1989, for which the maximum negative excursion of the Dst index was $-589 \mathrm{nT}$. During the main phase of the magnetic storm, the strong convection electric field with a spatially inhomogeneous structure appears in the inner magnetosphere between $L=2.0$ and 7.0. The averaged intensity of the electric field was in a range of about $2.5-9.2 \mathrm{mV} / \mathrm{m}$. The spatial distribution in the magnetic equatorial region indicates that the magnitude within an $L$-value range of 2.2-7.0 is much larger than that observed at $L=7.0-10.0$. Associated with the appearance of the strong convection electric field, the cold plasma density near the trough region around $L=3.0-6.0$ was enhanced with one or two order magnitude, compared with that in the magnetically quiet condition. This implies that a mount of the ionospheric plasma may be supplied from the topside ionosphere into the trough and plasmasphere regions by the frictional heating due to the fast plasma convection in the ionosphere as pointed out by previous studies on the enhancements of plasma density in these regions, based on incoherent scatter radar and total electron content (TEC) observations (e.g., Yeh and Foster, 1990; Foster et al., 2004). During the recovery phase of the magnetic storm, the convection electric field observed in the inner magnetosphere and plasmasphere regions recovers within 3-4 days almost up to the level of the magnetically quiet condition.

Key words: Magnetic storm, dawn-to-dusk electric field, inner magnetosphere and plasmasphere, plasmapause, reversed convection electric field, plasma density enhancements, duskside sector, frictional heating.
\end{abstract}

\section{Introduction}

It is essential to clarify variations of the large-scale electric field structure associated with geomagnetic activities such as sudden commencements (SCs), substorms and magnetic storms, for understanding of the physics of plasma dynamics and energy transport in the inner magnetosphere and plasmasphere. The electric field in the inner magnetosphere has been generally believed to consist of two components. One is the dawn-to-dusk convection electric field dominant in the region of the outer magnetosphere beyond the plasmapause. The origin of this convection electric field is considered as the interplanetary electric field in the solar wind, penetrating into the magnetosphere via the solar wind-magnetosphere interaction (e.g., Dungey, 1961, 1963; Levy et al., 1964; Nishida, 1968; Axford, 1969). The other is the co-rotation electric field directed earthward with dependence of the intensity on $r^{-2}(r$ denotes distance from the center of the earth). The co-rotation electric field generated by the ionospheric dynamo is dominant in the plasmasphere region $(L<4-6)$ (e.g., Axford and Hines, 1961; Nishida, 1966; Brice, 1967). Later, a large number of electric field models in the magnetosphere have been published

Copy right (C) The Society of Geomagnetism and Earth, Planetary and Space Sciences (SGEPSS); The Seismological Society of Japan; The Volcanological Society of Japan; The Geodetic Society of Japan; The Japanese Society for Planetary Sciences; TERRAPUB based on experimental and theoretical works (e.g., Volland, 1973; Maynard and Chen, 1975; Stern, 1973, 1977; Sojka et al., 1986).

Several reports on the electric field phenomena in the inner magnetosphere during a geomagnetic storm have been made, based on the in-situ observations (e.g., Heelis et al., 1976; Spiro et al., 1979; Maynard et al., 1980, 1983; Baumjohann et al., 1985; Baumjohann and Haerendel, 1985). A statistical analysis result of the electric field in the inner magnetosphere $(2.0<L<6.0)$ measured by the ISEE-1 satellite within a period of one year was made by Maynard et al. (1983), who showed that the magnitude of the electric field depends on $K p$ and AE indices and the typical magnitude in the equatorial plane $(L=2.5-5.0)$ is in a range between 0.2 and $0.8 \mathrm{mV} / \mathrm{m}$ in a frame co-rotating with the earth. During intense activity the electric fields become large occasionally exceeding $2 \mathrm{mV} / \mathrm{m}$. Maynard et al. (1983) also suggested that in the evening sector the plasma flow velocity is reduced, and in the morning sector it is enhanced in the inner magnetosphere due to the convection electric field. However, in these studies, because the cold plasma density structure in the inner magnetosphere was not shown, the relationship between the locations of the plasmapause and the peak magnitude of the electric field, and the variations of the electric field intensity corresponding to the density structure in this region have not 
yet been clarified. Furthermore, due to the very long orbital period (57 hours) of the ISEE-1 satellite, Maynard et al. (1983) could not discuss the description of the electric field variations in the inner magnetosphere associated with the evolution of a magnetic storm. Baumjohann et al. (1985) and Baumjohann and Haerendel (1985) presented observation results from the GEOS-2 electron gun experiment at geosynchronous orbit. The electric field at this radial position $(L=6.6)$ within a magnetic local time range from 06:00 to 21:00 scaled both with $K p$ index and with the solar wind electric field. Okada et al. (1993) reported that spatial and temporal variations of the intense electric field observed in the middle latitudes near the duskside during the giant magnetic storm occurred on March 13-15, 1989, using the Akebono satellite observations. The magnitude of the electric field was about $100 \mathrm{mV} / \mathrm{m}$ when projected to the ionosphere, and this corresponded to the plasma drift speed of about $1.8 \mathrm{~km} / \mathrm{sec}$. They found that the location of the peak magnitude of the electric field is in the low-density region outside the plasmapause. Rowland and Wygant (1998) showed an average statistical picture of the variations of the electric field of the $E y$ component in the GSE coordinate observed by the CRRES satellite. Their observation survey was the inner magnetosphere region in the magnetic local time sector between 12:00 and 04:00 within an $L$ value range from 2.5 to 8.5 . They revealed that character of the enhanced electric field can be written as a function of magnetic activity ( $K p$ index) and that the peak intensity between $0.6 \mathrm{mV} / \mathrm{m}$ and $1.0 \mathrm{mV} / \mathrm{m}$ is located at $L=4.5$ within a $K p$ index range from 4 to 7-. However, the detail behavior of the electric field of the $E y$ component in the dawnside inner magnetosphere regions has not yet been clarified due to fewer observations in this sector within a magnetically distributed period $(K p>3)$. Furthermore, comparison analysis of the electric field in the inner magnetosphere with solar wind parameters, Dst index as well as cold plasma density structure in this region has been needed. Wygant et al. (1998) found a large-scale electric field penetrating into the inner magnetosphere with the peak magnitude of $6 \mathrm{mV} / \mathrm{m}$ located at $L=2-4$ during the main phase of the magnetic storm on March 24-27, 1991 by using the CRRES satellite data. These magnitudes were larger than quiet time values of the electric field by a factor of 60 or more. Wygant et al. (1998) also indicated that the electric field is systematically diminished or shielded near the inner edge of the ring current during the recovery phase of the magnetic storm and that evidence for regions of reversed convection near midnight during the recovery phase is provided.

Ionospheric currents associated with plasma convection in the ionosphere produce distinctive signatures of geomagnetic field variations observed by ground-based magnetometers. By analyzing the magnetometer records, we can divide the ionospheric currents into two components of DP (Disturbance of Polar region) 1 and DP 2. DP 1 currents are associated with substorm current wedges and are spatially limited to the midnight local time sector (Clauer and Kamide, 1985). DP 2 currents are driven by the global convection system (Nishida, 1968). Wilson et al. (2001) showed global electrodynamics in the inner magnetosphere during the initial and main phases of the magnetic storm on July 8-9, 1991, based on the analysis results of both ground-based and satellites' observations. They concluded that during the magnetic storm, the electric fields which were responsible for transport and energization of ring current particles were mostly associated with the DP 2 current system. They also concluded that in the evening sector penetration of the electric fields during the initial and main phases led to the formation of upward moving equatorial plasma bubbles that were detected by two DMSP satellites in the topside ionosphere. However, in these studies, it has not yet been clarified that the response of plasma density structure in the plasmasphere and the temporal development of the penetration of the electric field in the inner magnetosphere referring the onset of the southward turning of the IMF.

On the other hand, a strong convection electric field in the ionosphere during the magnetic storm based on ionospheric radar observations indicates a similar tendency of that of the magnetospheric observations has been reported by several workers. Based on the Millstone Hill $\left(42.6^{\circ} \mathrm{N}\right.$, $71.5^{\circ} \mathrm{W}$ ) midlatitude ionospheric radar observations, Yeh $e t$ al. (1991) showed that a strong convection electric field exists in the duskside ionosphere between $L=2$ and $L=4$ during the main phase of an intense magnetic storm with the Dst minimum value of about $-320 \mathrm{nT}$ which occurred on February 8, 1986. The peak value of the electric field was about $30-40 \mathrm{mV} / \mathrm{m}$ at $L=2.4-3.0$. They also found that the location of the peak value of the electric field lies between the equatorward edges of the electron and soft $(<1 \mathrm{keV})$ ion precipitation in the low conductivity region from the simultaneous DMSP satellite observations. Goncharenko et al. (2004) found the existence of a strong convection electric field with the magnitude of about 30-120 $\mathrm{mV} / \mathrm{m}$ in both the dawnside and duskside ionospheric $\mathrm{E}$ regions $(100-150 \mathrm{~km})$ at mid-latitudes during several intense magnetic storms $(K p=8-9)$ by using the incoherent scatter radar at Millstone Hill. Their observation results revealed E region zonal plasma drifts of 300-1000 m/sec, westward in the evening sector and eastward in the morning sector which correspond to the ionospheric convection pattern. Goncharenko et al. (2004) showed that the tidal pattern of neutral winds in the lower thermosphere is heavily disrupted and that the zonal component of the neutral wind follows convection-driven ion flow.

The feature of the magnetic and electric field perturbations and high energy particle modulations during SCs in the inner magnetosphere has been well known (e.g., Knott et al., 1985; Laakso and Schmidt, 1989; Cahill et al., 1990; Blake et al., 1992; Li et al., 1993; Wygant et al., 1994; Wilson et al., 2001; Shinbori et al., 2004a, 2004b). A case study of an SC event which occurred on March 24, 1991 observed by the CRRES satellite was reported by Wygant et al. (1994), who showed that the electric and magnetic field perturbation with the bipolar waveform in the inner magnetosphere $(L=2.6)$ at the nightside $(02: 40$ MLT $)$ have large amplitude of about $80 \mathrm{mV} / \mathrm{m}$ and $140 \mathrm{nT}$, respectively. Furthermore, they also showed that the injection of the energetic electron within an energy range of 15 $\mathrm{MeV}$ occurs with correspondence to the period of the electric field perturbations. The data analysis result of the long- 
term observations of plasma waves and electric and magnetic field variations obtained by the Akebono satellite was reported by Shinbori et al. (2003, 2004a, b). Shinbori et al. (2004a) showed that 126 cases of the electric field variations associated with SCs which occurred more than 13 years since March 1989 show an abrupt change of intensity with the amplitude range of $0.2-38 \mathrm{mV} / \mathrm{m}$ as well as direction within a few minutes inside the plasmasphere. The initial excursion of the electric field during SCs tends to be directed westward. Shinbori et al. (2004a) also found that a DC offset of the $E y$ component of the electric field appears after the initial electric field impulse associated with SCs. This signature is interpreted to be a magnetospheric convection electric field penetrates into the inner plasmasphere $(L=2.5)$. The intensity of the offset of the $E y$ field gradually increases by $0.5-2.0 \mathrm{mV} / \mathrm{m}$ about $1-2$ minutes after the onset of the initial electric field impulse and persists about 10-30 minutes.

However, because majority of these previous studies on the in-situ electric field phenomena during a magnetic storm in the inner magnetosphere has been based on the satellite observations with the equatorial orbit and orbital period of more than 10 hours (e.g., Maynard et al., 1980; Wygant et $a l ., 1998)$, the signature of the electric field inside the plasmasphere and the response of the plasmasphere have not been fully understood at the point of the high time variations and meridional spatial distribution in almost the same magnetic local time sector. In this paper, relationship between the electric field and cold plasma density structures during a super magnetic storm is studied by using electric field (Hayakawa et al., 1990) and plasma wave data (Oya et al., 1990) for more than 15 years of the Akebono satellite observations with a high time resolution. In the present data analysis, a strong dawn-to-dusk electric field in the inner magnetosphere and plasmasphere has been identified during the main phase of the magnetic storm which occurred on March 13-15, 1989. During the main phase of a major magnetic storm, the strong dawn-to-dusk electric field appeared with the average intensity of $2.0-9.0 \mathrm{mV} / \mathrm{m}$ in the inner magnetosphere and plasmasphere regions. The electric field intensity was much stronger near the plasmapause $(L=3)$ than at more distant positions $(L>5)$.

The purpose of the present paper is to report the detail signatures of electric field and cold plasma density distribution in each phase of the super magnetic storm which occurred on March 13-15, 1989, and to compare the relationship between the plasma density structure of the plasmasphere and the electric field signature with the progress of the super magnetic storm.

\section{Observation Data}

Observations of the Akebono satellite have been continued more than 15 years since the launch on February 21, 1989 when the satellite was put into a semi-polar orbit with an inclination of $75^{\circ}$, with initial apogee and perigee of $10,500 \mathrm{~km}$ and $274 \mathrm{~km}$, respectively. In the present studies, electric field and plasma wave data are provided by instruments of electric field detector (EFD) (Hayakawa et al., 1990) and high frequency plasma wave detectors and sounders (PWS) (Oya et al., 1990), respectively. Time res- olution of the EFD data from the science data base of the Akebono satellite is 8 seconds. The data are presented in the Geocentric Solar Magnetospheric (GSM) coordinate system. The electric field measurement is made by two sets of double probes in the spin plane of the Akebono satellite. The spin axis component (the $E x$ component) have been calculated under the assumption of zero electric field along the magnetic field line, namely $\overrightarrow{\mathrm{E}} \cdot \overrightarrow{\mathrm{B}}=0$. In this paper, we plotted the electric field intensity of the dawn-to-dusk component in a co-rotating frame as a function of $L$-value mapped to the equatorial region of the inner magnetosphere by using the mapping method proposed by Mozer (1970). It is noted that errors in the measurements of $E y$ and $E z$ induce errors in $E x$ with the scale of $B y / B x$ and $B z / B x$. However, since the orbit of the Akebono satellite is almost in agreement with the dawn-to-dusk plane during the period of the super magnetic storm on March 13-15, 1989, the contribution of the Ex component to the dawn-to-dusk electric field is evaluated as a small value. Therefore, we used the two components ( $E y$ and $E z$ ) for the present analysis. On the other hand, time resolution and frequency range of the PWS data are 2 seconds and $20 \mathrm{kHz}$ to $5.1 \mathrm{MHz}$, respectively. We also used geomagnetic field data obtained from Kakioka Magnetic Observatory and SYM-H indices with the time resolution of 1 minute. The SYM-H value is global index for measuring the varying magnitude of the symmetric ring current (see Iyemori and Rao, 1996). During the period of the magnetic storm occurred on March 13-15, 1989, the apogee of the Akebono satellite orbit was located at $L=3.26$, ALT $=10455.8 \mathrm{~km}$ and MLAT $=-25.91$ deg of the duskside plasmasphere (MLT: 16:00-20:00).

\section{Response of the Inner Duskside Magnetosphere during a Super Geomagnetic Storm on March 13-15, 1989}

\subsection{Summary of super geomagnetic storm}

Figure 1 shows one minute averages of the SYM-H index and geomagnetic field variation of the H-component measured at Kakioka within a period of March 12-16, 1989. Some portion of the variation of the SYM-H index indicates an abrupt increase of the geomagnetic field due to the sudden compression of the magnetosphere by increases of solar wind dynamic pressure. Unfortunately, in this period, the solar wind data were not available and they are not included in this plot. In addition, since ring current particles may be lost through scattering into the ionosphere, charge exchange, or convection into the magnetopause, the SYM$\mathrm{H}$ index is sensitive to these loss mechanisms; then, it is not simply contributable to injection of ring current particles. Therefore, if the variations of the SYM-H index are constant, it indicates that the ring current particles injected due to a large-scale electric field are balanced by loss mechanisms. Periods of I, II, III and IV in this plot correspond to the pre-storm phase, the initial phase, the main phase and the recovery phase, respectively. The arrows with labels A$\mathrm{N}$ in the bottom panel correspond to the panels of $\mathrm{A}-\mathrm{N}$ in Figures from 4 to 6 in the following section.

The SYM-H index gives an averaged value of almost 0 nT within the pre-storm phase I prior to the onset of SC at 01:24 (UT) on March 13. This means that the magnetic con- 


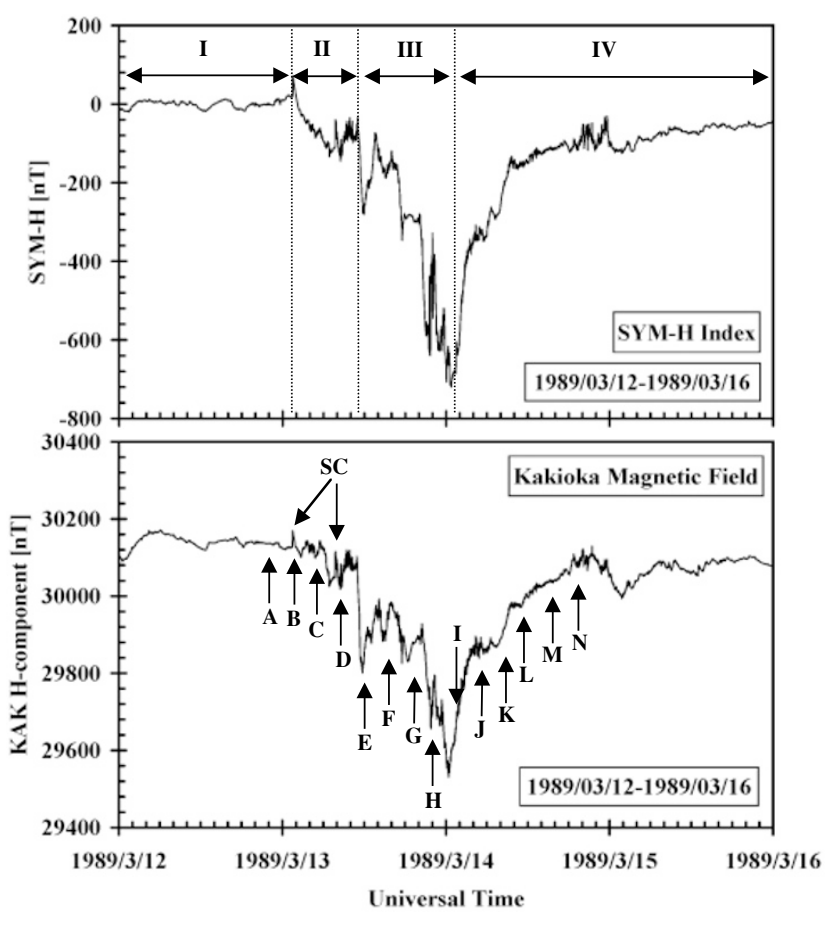

Fig. 1. Summary of the magnetic storm of March 13-15, 1989. The upper and bottom panels show the geomagnetic index (SYM-H) and geomagnetic H-component variations at Kakioka, respectively. Fourteen arrows with labels $\mathrm{A}-\mathrm{N}$ in the bottom panel indicate the period in the data set of Figs. 3-5. The horizontal arrows I, II, III, and IV in the upper panel present the pre-storm phase, initial phase, main and recovery phases of this storm, respectively.

dition in the inner magnetosphere and plasmasphere is very quiet and that the large-scale convection electric field intensity and injection of ring current particles may be weak. The geomagnetic field of the H-component at Kakioka also shows a faint variation around $30100 \mathrm{nT}$.

Both in the upper and bottom panels of Fig. 1, the SYM$\mathrm{H}$ index and the geomagnetic field variations of the $\mathrm{H}$ component at Kakioka show an abrupt increase within a few minutes at 01:26 (UT) on March 13. This phenomenon is an SC signature which occurs due to the sudden compression of the magnetosphere by the encounter of the interplanetary shock or discontinuity into the magnetopause (e.g., Araki, 1994). The SYM-H index and the geomagnetic field variations during the SC give the maximum values of $72 \mathrm{nT}$ and $30169.5 \mathrm{nT}$, respectively. From this result, the SC amplitudes in the SYM-H index and the geomagnetic field variations at Kakioka are also $54 \mathrm{nT}$ and $43.2 \mathrm{nT}$. It is noted that the SC amplitude recorded at Kakioka is about 0.8 times as small as that of the SYM-H index. At the onset time of $\mathrm{SC}$, the Kakioka station was located in the magnetic local time sector of 10:26 (MLT). The SC amplitude measured in low and middle latitudes tends to become small due to the enhanced ionospheric current during SC (e.g., Araki, 1994).

During the period II of the initial phase after the onset of the SC, the SYM-H index presents a gradual decrease of about $180 \mathrm{nT}$ within a period of about 5.5 hours. This signature indicates a gradual development of the ring current in the inner magnetosphere after the onset of the SC. On the other hand, the geomagnetic field variations at Kakioka show also decreasing of about $143 \mathrm{nT}$ with a small perturbation within the same period of the signature of the SYM-H index. At 07:43 (UT) on March 13 in the initial phase II, the SYM-H index and the geomagnetic field variations of the H-component at Kakioka show an abrupt increase within a few minutes. This variation also indicates an SC signature associated with the sudden compression of the magnetosphere by the encounter of the interplanetary shock or discontinuity into the magnetopause. After the second SC in the super geomagnetic storm, both the panels show a small perturbation with the amplitude of about $40 \mathrm{nT}$ and the perturbation persists until 11:00 (UT).

During the period III of the main phase, the SYM-H index and the geomagnetic field variations at Kakioka show a steep negative slope, and reached the minimum value of $-720 \mathrm{nT}$ at 00:46 (UT) and 29530.8 nT at 00:23 (UT) on March 14, respectively. These pictures indicate that the ring current intensity abruptly grew in the inner magnetosphere due to the enhancement of the large-scale convection electric field associated with the southward turning of the interplanetary magnetic field (IMF). It is noted that the geomagnetic field variations at Kakioka in the period from 11:45 (UT) to 20:29 (UT) present several large perturbations with the amplitude of about 40-80 nT although the perturbations are not found in the SYM-H index. Taking into account the magnetic local time at Kakioka within a period when the perturbations take place, it seems that the variations are positive bays associated with occurrence of the magnetospheric substorm.

During the period IV of the recovery phase, both the panels indicate a gradual increase to the quiet level for two days with a small perturbation. From the variations of the SYM-H index, the injection of ring current particles ceases due to the decrease of the convection electric field intensity to the magnetically quiet level, and loss process of the ring current particles through pitch angle scattering and charge exchange is making progress (Wygant et al., 1998; Daglis et al., 1999; Wilson et al., 2001).

\subsection{Identification of cold plasma density and plasma- pause location in the inner magnetosphere}

The upper panel of Fig. 2 shows an example of the dynamic spectrum of plasma waves within a frequency range from $20 \mathrm{kHz}$ to $5.1 \mathrm{MHz}$ provided from the PWS instrument. The horizontal axis of each panel represents universal time and satellite location. The white line in the dynamic spectrum gives the local electron cyclotron frequency calculated from the IGRF model field, and the upper red marks in each dynamic spectrum indicate the magnetic equator. In this case, the Akebono satellite passed through the duskside plasmasphere across the magnetic equator. The time period of the dynamic spectrum corresponds to the early recovery phase of the super geomagnetic storm which occurred on March 13-15, 1989. In the dynamic spectrum, two banded spectra of plasma waves which appear above the electron cyclotron frequency are upper hybrid resonance (UHR) and Z-mode waves, respectively. The UHR waves are continuously observed throughout the orbital motion of the Akebono satellite in the inner magnetosphere. The upper cut-off frequency $\left(f_{\mathrm{UHR}}\right)$ of the UHR waves is given as the follow- 

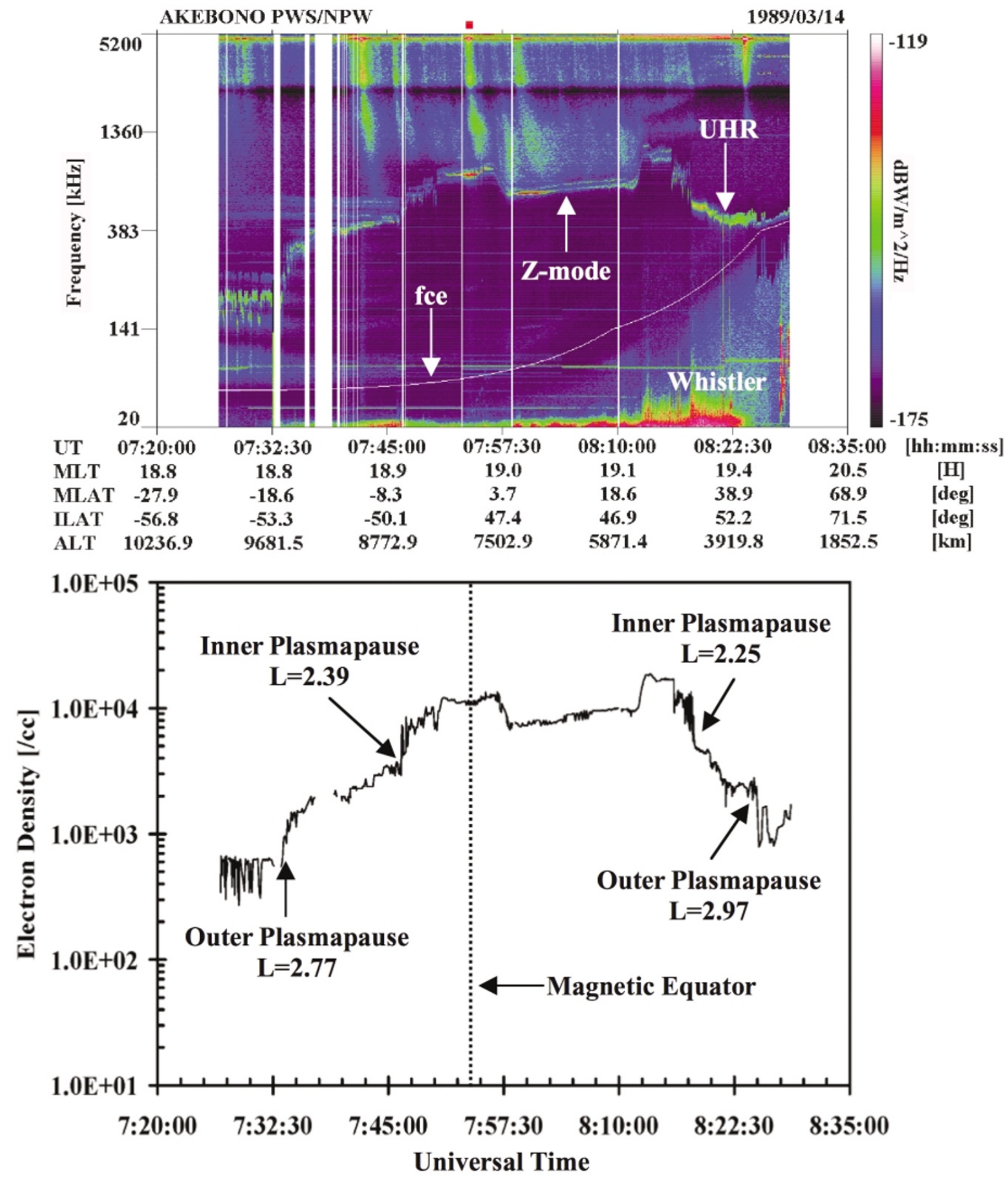

Fig. 2. An example of the dynamic spectrum of plasma waves within a frequency range from $20 \mathrm{kHz}-5.1 \mathrm{MHz}$ obtained by the PWS instrument onboard the Akebono satellite and the cold plasma density profile determined from the upper cut-off frequency of the upper hybrid resonance (UHR) waves as a function of time and satellite position. The color codes in the upper panel give the plasma wave intensity as a unit of $\mathrm{dBW} / \mathrm{m}^{2} / \mathrm{Hz}$. The white curves in this panel indicate trends of the electron cyclotron frequency. The UHR, $Z$-mode and whistler mode waves can be clearly seen in the dynamic spectrum. The obtained plasma density profiled along the satellite in the low magnetic latitude in the northern hemisphere, in this case, shows depression by $1 / 3$ of the equator region. From the definition of the location of the plasmapause in the present study, we can identify the northern and southern outer plasmapauses as $L=2.77$ and 2.97, respectively.

ing equation,

$$
f_{\mathrm{UHR}}=\sqrt{f_{c e}^{2}+f_{p e}^{2}},
$$

where $f_{p e}$ and $f_{c e}$ are the local electron plasma and cyclotron frequencies, respectively. Therefore, we can derive the cold plasma density from the above relation. On the other hand, since the plasma parameter $\left(f_{p e} / f_{c e}\right)$ often becomes less than 1.0 in the auroral zone and polar cap re- gions outside the plasmasphere, we derived the cold plasma density from the upper cut-off frequency of the whistler mode waves, that is, the plasma frequency in order to obtain the density data with high accuracy. The plasmapause is defined as the steepest density gradient in the inner magnetosphere (Carpenter, 1966). Referring the definition of plasmapause by Carpenter and Anderson (1992), we first identify the locations of the steep density gradient which 
indicates that the cold plasma density abruptly decreases by a factor of 5 or more than within $\Delta L<0.5$ within an $L$ value range of 1.0-10.0 in the inner magnetosphere. Next, we select the location of the maximum steep plasma density gradient as the plasmapause.

In the case of the cold plasma density profile shown in the bottom panel of Fig. 2, the plasma density shows two step structure with abrupt decreases by a factor of 9 and 4 at $L=2.77$ and 2.39 within $\Delta L=0.03$ and 0.003 , respectively, in the southern hemisphere. From the above definition of the plasmapause, we can determine the locations of the southern inner and outer plasmapauses as $L=2.39$ and 2.77 , respectively. Here, we used the method of magnetic field trace in the IGRF model in order to calculate $L$ value. On the other hand, also in the northern hemisphere, the plasma density indicates two step structure with abrupt decreases by a factor of 7 and 16 at $L=2.25$ and 2.97 within $\Delta L=0.06$ and 0.04 , respectively. Then, the locations of the northern inner and outer plasmapauses were determined at $L=2.25$ and 2.97 , respectively. We adapted the outer plasmapause in the present analysis. It is interesting that the plasma density profile in the bottom panel of Fig. 2 shows a density depression from 12821 [/cc] to 7388 [/cc] around 07:58 (UT) in the northern plasmasphere regions. This characteristic feature of the plasma density profile is called as the "Donkey Ears" phenomenon by Oya (1991, 1997, 2004). The arrows in each panel of the figures shown in the following sections indicate the location of the plasmapause determined from the above definition.

3.3 Evolution of plasma density structure and electric field in the inner magnetosphere and plasmasphere regions

In this section, the morphology and evolution of the plasma density structure and dawn-to-dusk electric field variations are discussed for the pre-storm phase, SC, the initial, main and recovery phases of the magnetic storm. The important physical process is the penetration of the electric field into the inner magnetosphere and inside the plasmasphere, which is able to inject the plasma sheet particles into these regions, to energize these particles with the first invariance conservation and to modify the cold plasma density structure of the plasmasphere.

Figure 3 shows the configuration of the Akebono satellite orbit in the inner magnetosphere during the super magnetic storm on March 13-15, 1989. As shown in the panel (a) in Fig. 3, the perigee and apogee of the Akebono satellite orbit was located at $L=1.21$, ALT $=286.4 \mathrm{~km}$ and MLAT $=22.32 \mathrm{deg}$ in the dawnside sector (MLT: 04:00-08:00) and at $L=3.26$, ALT $=10455.8 \mathrm{~km}$ and MLAT $=-25.91 \mathrm{deg}$ in the duskside sector (MLT: 16:0020:00), respectively. The orbital interval indicated as both two blue circles presents display area of the present observation data shown in each panel in the following Figs. 4-6. From the panels (b) and (c), the altitude of the Akebono satellite passage in the duskside sector within a magnetic local time range from 19.3 to 20.3 hours decrease from $6000 \mathrm{~km}$ to $2000 \mathrm{~km}$ as an $L$-value increases from 2.0 to 10.0. Then, these panels mean that the Akebono satellite passes through the low altitude $(<3000 \mathrm{~km})$ region outside the plasmasphere $(L>4.0)$.
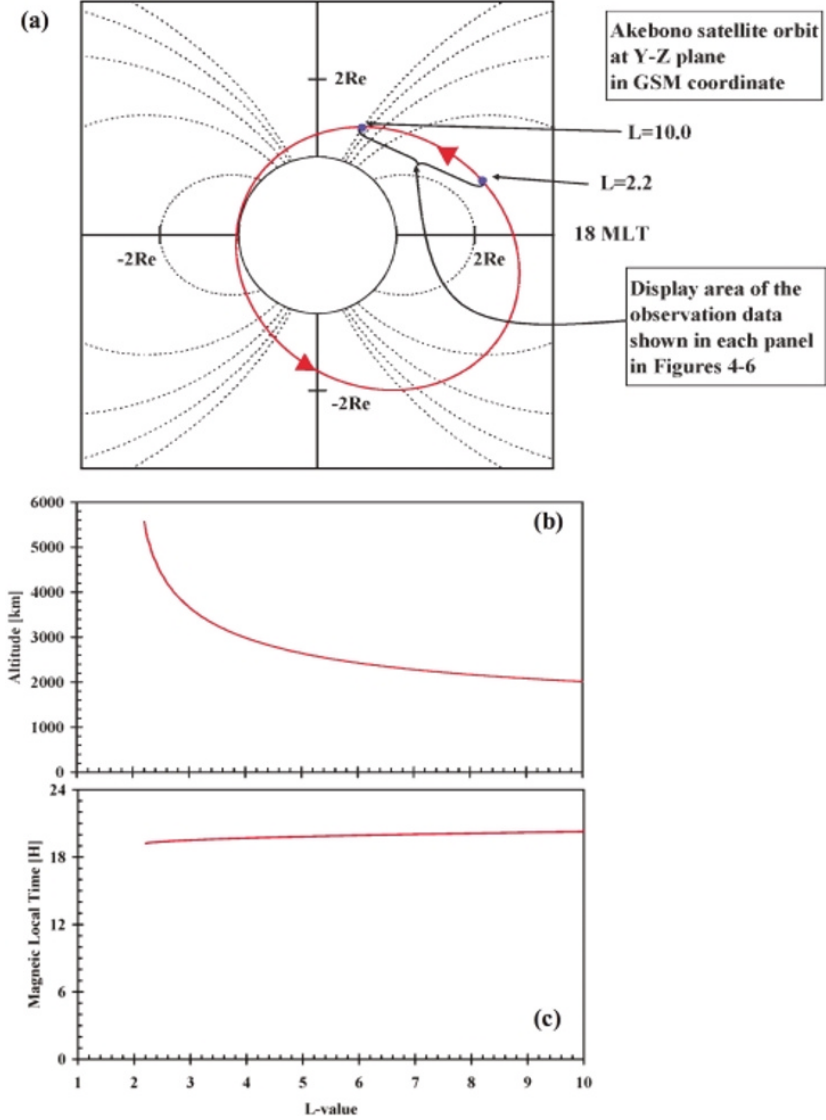

Fig. 3. Configuration of the Akebono satellite orbit on March 13-14, 1989 during the super magnetic storm. The panel (a) gives an Akebono satellite orbit at the $Y-Z$ plane in GSM coordinate as a red line and geomagnetic field line calculated from the IGRF 90 model as dashed lines. The interval given as two blue circles corresponds to the display area of the observation data shown in the following figures. The panels (b) and (c) indicate the Akebono satellite orbit plotted with $L$-value versus altitude and $L$-value versus magnetic local time, respectively.

Figures 4-6 show the cold plasma density near the location of the Akebono satellite obtained from the upper cut-off frequency of the UHR waves and the electric field data of dawn-to-dusk component in a co-rotation frame as a function of $L$-value. Considering the geometry of the magnetic field line, the electric field intensity is mapped to the equatorial plane assuming that there is no parallel electric field component along the magnetic field line. The notation of Lpp in each panel from A to $\mathrm{N}$ in Figs. 4-6 indicates the $L$ value of the location of the plasmapause determined from our plasmapause definition mentioned in Section 3.2. It should be noted that the Akebono satellite passed from the low latitude region to the high latitude region in the northern hemisphere. Therefore, time increases from left to right in the panels $(\mathrm{A}-\mathrm{N})$ of both the cold plasma and electric field profiles.

3.3.1 Pre-storm phase (A and B) The panels A and $\mathrm{B}$ in Fig. 4 present the cold plasma density and the electric field intensity of the dawn-to-dusk component prior to the onset of SC. The cold plasma density profile in the left panel A shows a smooth decrease as a function of the $L$ value within an $L$-value range from 2.3 to 5.1 in the plasmasphere. The variation of the cold plasma density indicates 

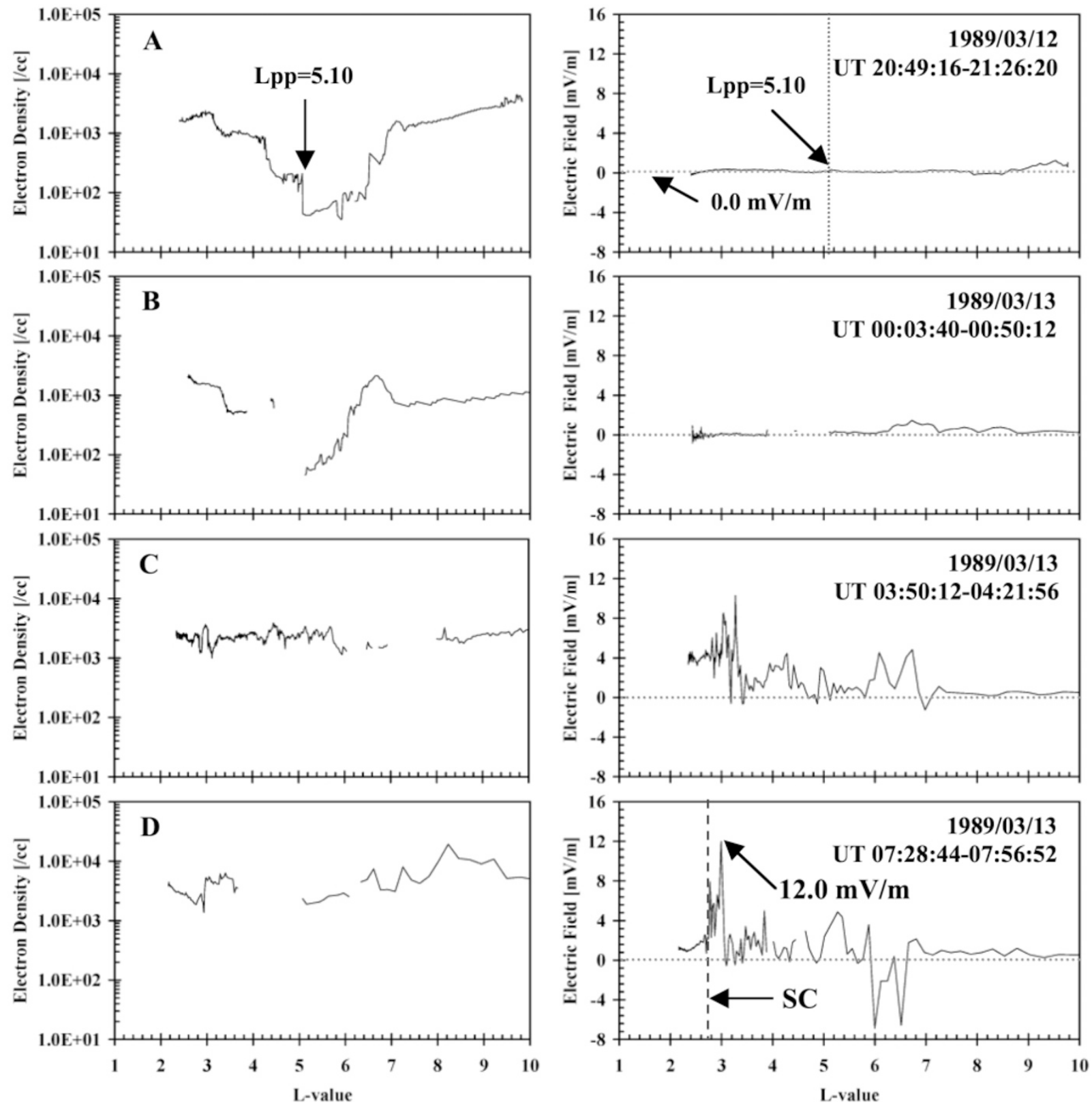

Fig. 4. Distributions of cold plasma density obtained from the upper cut-off frequency of the UHR waves in the PWS data and electric field intensity of the dawn-to-dusk component in the earth's co-rotating frame plotted as a function of $L$-value for the seven passages of the Akebono satellite in the inner magnetosphere and plasmasphere during the super magnetic storm on March 13-15, 1989. The horizontal dotted line in each right panel in this figure gives the value of the electric field intensity as $0.0 \mathrm{mV} / \mathrm{m}$. The black arrows and notations of "Lpp" in panels of A-D indicate the plasmapause location for each passages of the Akebono satellite.

an abrupt decrease from $100 /$ cc to $30 /$ cc around $L=5.10$. This signature shows that the Akebono satellite encounters to the plasmapause. Although the plasma density profile shows an increase outside the plasmapause again, this density increase is due to the orbital character of the Akebono satellite as shown in Fig. 3. In the present analysis, the plasma density profile outside the plasmapause includes information on both the low altitude $(<3000 \mathrm{~km})$ and $L$-value structures of the plasma density in the auroral zone and polar cap region. This picture is true of the following plasma density profile in the present paper. The electric field of the dawn-to-dusk component in the right panel $\mathrm{A}$ is in a range of -0.2 to $0.4 \mathrm{mV} / \mathrm{m}$ or less within an $L$-value range from 2.2 to 9.0. The distribution of the electric field intensity in the plasmasphere region of $L<5.1$ shows a spatial homogeneity with a small value of less than $0.3 \mathrm{mV} / \mathrm{m}$. Its distribution indicates a typical signature of the dawn-to-dusk electric field inside the plasmasphere during a magnetically quiet condition. This evidence implies that the plasmaspheric plasma moves with a co-rotation lag from the earth's rotation. It is noted that the electric field intensity is a little enhanced within an $L$-value range of $L=5.0-5.3$ with the maximum intensity of about $0.3 \mathrm{mV} / \mathrm{m}$ at $L=5.2$.

As shown in the left panel $\mathrm{B}$ during the next orbital period before the onset of SC, the cold plasma density profile shows almost the same structure as that in the left panel $\mathrm{A}$ although there are several data gapes in the region around $L=4.5$. From this cold plasma density profile, it seems 

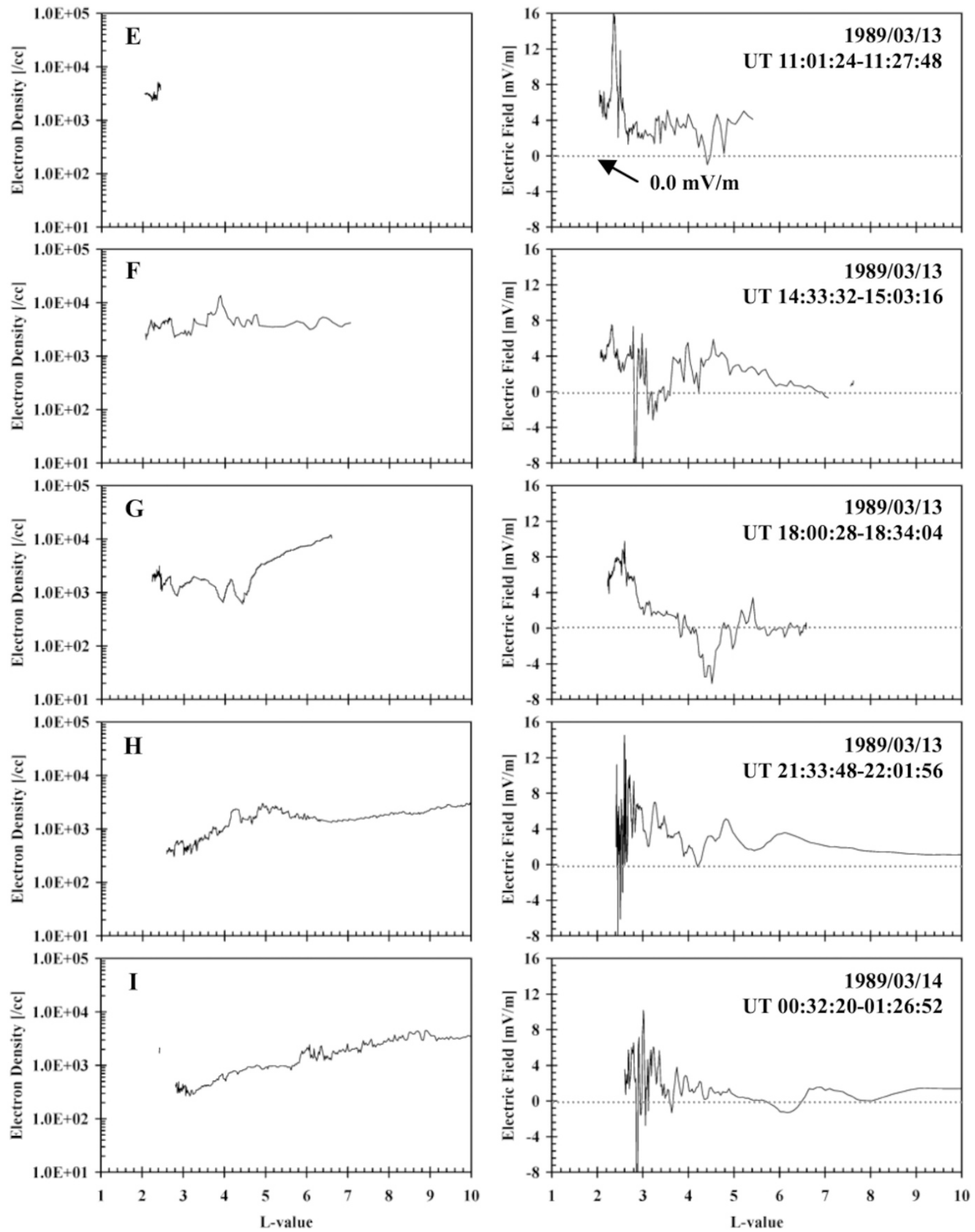

Fig. 5. Distributions of cold plasma density and electric field intensity for the seven passages of the Akebono satellite in the duskside plasmasphere. The format is the same as Fig. 4.

that the plasmapause might be located at $L=4.6$. On the other hand, the electric field of the dawn-to-dusk component distributes with almost the same structure as shown in the right panel A except for the region of $L=6.2$ to 7.3 , where the electric field intensity is about $1.0-1.5 \mathrm{mV} / \mathrm{m}$ with the peak magnitude of $1.5 \mathrm{mV} / \mathrm{m}$ at $L=6.7$. This region is mapped to the ionosphere in the sub-auroral region within a latitude range from $66.4^{\circ}$ to $68.2^{\circ}$. Therefore, it is seemed that the localized electric field is related to subauroral ion drift (SAID) phenomena with a latitudinally narrow $\left(\sim 1^{\circ}-2^{\circ}\right)$ regions of rapid westward drift (sometimes exceeding $5 \mathrm{~km} / \mathrm{sec}$ ) located equatorward of the auroral oval dominantly in the duskside sector associated with substorm (e.g., Anderson et al., 2001). Above $L=7.3$, the electric 

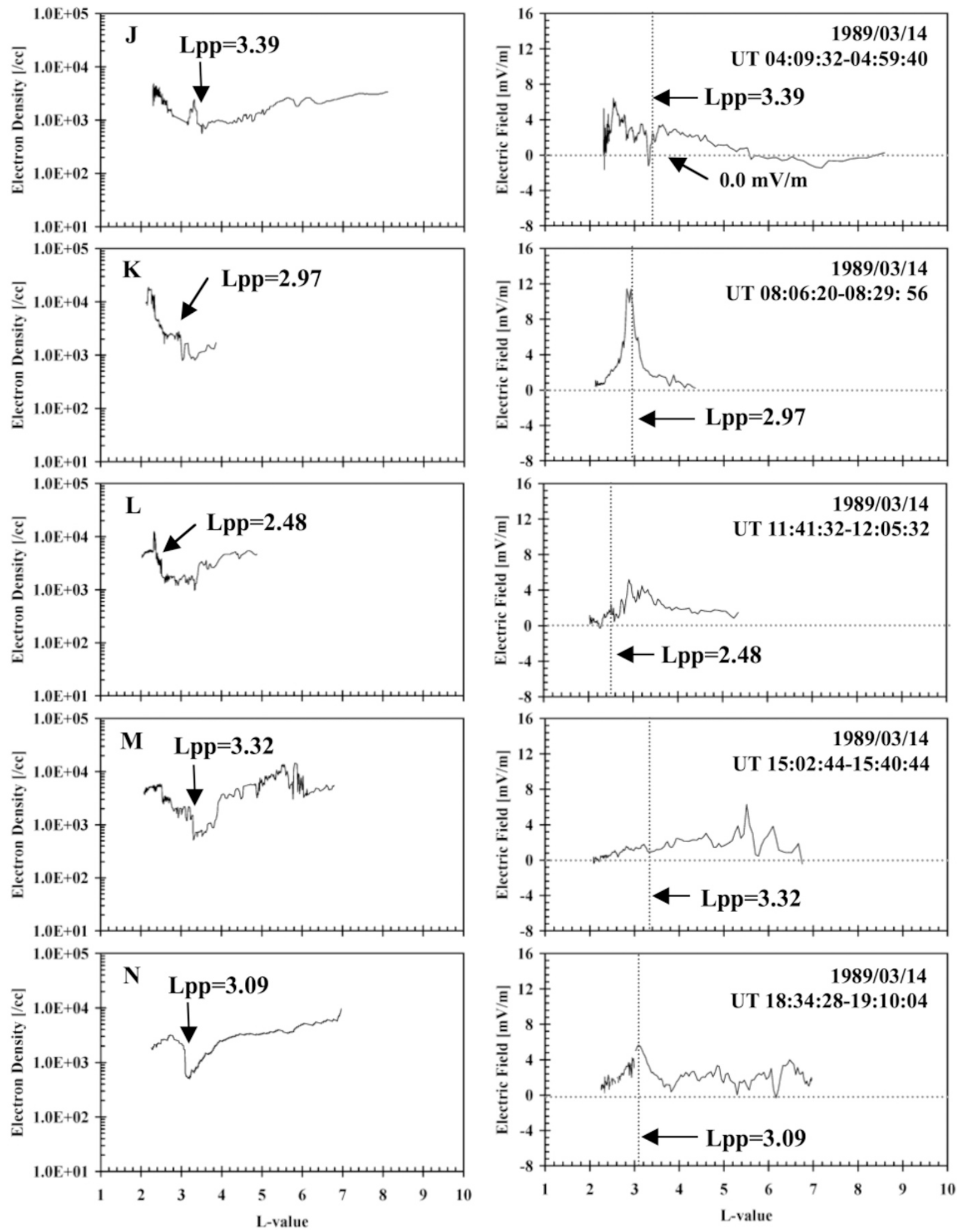

Fig. 6. Distributions of cold plasma density and electric field intensity for the seven passages of the Akebono satellite in the duskside plasmasphere. The format is the same as Fig. 4.

field data have a significant dawn-to-dusk component with the magnitude of the order of $0.5 \mathrm{mV} / \mathrm{m}$ or more.

3.3.2 Initial phase ( $C$ and $\mathbf{D})$ In the left panel $C$ in Fig. 4 during the initial phase after the first onset of SC, the cold plasma density profile shows a spatially homogeneous distribution with a small fluctuation in the entire regions of the plasmasphere, auroral zone and polar cap. The plasma density in these regions was about 2000 /cc. In this case, the plasma density structure in the inner magnetosphere indicates a different distribution from that shown in the left panels A and B in this figure. This variation of the plasma density does not have a signature of the plasmapause and 
trough regions. The above result shows that the plasma density within an $L$-value range of 3.0-7.0 increases with one or two order variations within a time period of less than 3 hours. On the other hand, the electric field data show a spatially inhomogeneous distribution with the magnitude of $1.2-10.3 \mathrm{mV} / \mathrm{m}$ in the inner magnetosphere region of $L<7.0$. The averaged intensity in this region was about $3.8 \mathrm{mV} / \mathrm{m}$ within an $L$-value range of 2.3 to 3.4 . The electric field intensity in the polar cap region of $L>7.0$ indicates almost the spatially homogeneous distribution with the magnitude of $0.2-0.6 \mathrm{mV} / \mathrm{m}$. The averaged magnitude of the electric field was about $0.3 \mathrm{mV} / \mathrm{m}$. It is noted that the electric field intensity of the dawn-to-dusk component in the inner magnetosphere region of $L<7.0$ is about 12 times stronger than that in the polar cap region of $L>7.0$. From the above analysis results of the electric field, the background plasma with a low energy range convects to the sunward direction with the velocity of $1.7 \mathrm{~km} / \mathrm{sec}(L=2.1)$ to $8.0 \mathrm{~km} / \mathrm{sec}(L=4.0)$. Therefore, this evidence suggests that the plasmaspheric plasma no longer co-rotates with the earth's rotation at this time.

In both the left and right panels D of Fig. 4 corresponding to the initial phase of the magnetic storm, the second SC event which occurred at 07:43 (UT) on March 13 is included. The structure of the cold plasma density in the inner magnetosphere and plasmasphere regions is almost the same as that without an abrupt decrease of the plasma density in a narrow region of $\Delta L<0.5$ in the left panel D of Fig. 4 although there is the data gap within an $L$-value range of 3.6-5.0. It is noted that the cold plasma density gradually increases from 2000 /cc to 5000 /cc within an $L$ value range of 3.0-3.6 after the onset of SC. On the other hand, the electric field signature indicates an abrupt change within a few minutes at the onset of SC due to the compression of the magnetosphere by the shock wave triggered by the arrival of the interplanetary shock wave to the earth's magnetopause around 07:43 (UT). The initial excursion of the electric field which appeared at $L=2.7$ and 19:25 MLT indicates the large amplitude of $12.0 \mathrm{mV} / \mathrm{m}$ and short time scale of about 2 minutes. The dawn-to-dusk component at the equatorial plane utilized in this plot is too coarse to resolve the full amplitude of the electric field associated with SC. From the three components of the electric field at the Akebono satellite position, the full amplitude and direction of the initial excursion were about $86.8 \mathrm{mV} / \mathrm{m}$ and sunward, respectively. The variations of the electric field persist for about 128 seconds. The electric field variations suggest that the compressinal wave front passed through the location of the Akebono satellite (e.g., Shinbori et al., 2004a). After the impulsive electric field variations, the electric field data indicate a DC offset with the averaged amplitude of about $2.0 \mathrm{mV} / \mathrm{m}$ in the inner magnetosphere within an $L$-value range of 3.0-6.4. This signature implies that the dawn-todusk convection electric field is enhanced in this region associated with the abrupt compression of the magnetosphere. Furthermore, within an $L$-value range of 5.9 to 6.7 , the dawn-to-dusk electric field is directed in the dusk-to-dawn direction with the maximum amplitude of about $6.9 \mathrm{mV} / \mathrm{m}$ at $L-6.0$. This electric field signature indicates that the background plasma in the equatorial region of the magne- tosphere flows in the anti-sunward direction with a speed of about $47 \mathrm{~km} / \mathrm{sec}$.

3.3.3 Main phase (E, F, $\mathbf{G}$ and $\mathbf{H}$ ) In the left panels of $\mathrm{E}$ to $\mathrm{H}$ in Fig. 5 corresponding to the period of the main phase of the magnetic storm, the cold plasma density profile is shown for time interval of about 3 hours. Because the PWS instrument was not operated in a region of more than $L=2.4$ within a period of the panel $E$, the cold plasma density profile in this region is not shown. In these cases, we cannot identify the location of the plasmapause from the plasma density variations following our definition already mentioned in Section 3.2. The variations of the plasma density indicate a gradual decrease from 4600 /cc (panel F) to 400 /cc (panel H) in the inner magnetosphere within an $L$-value range of 2.2-4.0 associated with the progress of development of the ring current. The structure of the plasma density in the inner magnetosphere region within an $L$-value range of less than 5.0 shows a smallscale ( $\Delta L \sim 0.02-0.2$ ) irregularity with the variations of the plasma density from 300 /cc to 2000 /cc. It should be noted that the plasma density in the region of $L>4.4$ shown in the left panel $G$ of Fig. 5 increases about 3-4 times larger compared with those in the left panels $\mathrm{F}$ and $\mathrm{H}$. This implies that the cold plasma in this region may be supplied from the sub-auroral ionosphere due to the frictional heating by the enhanced convection during the main phase of the magnetic storm as pointed out by previous studies on the enhancements of plasma density in these regions, based on incoherent scatter radar and total electron content (TEC) observations (e.g., Yeh and Foster, 1990; Foster et al., 2004). Yeh and Foster (1990) demonstrated that generation mechanism of enhanced ion outflow phenomena during a magnetic storm is an enhancement of ring current precipitation and rapid ion convection in the ionosphere. In the case of the panel $\mathrm{G}$ in Fig. 5, a region of the enhanced convection electric field almost corresponds to that of an abrupt enhancement of the plasma density within an $L$-value range of 4.0-6.6. The plasma flow velocity at the altitude of Eregion in the ionosphere region deduced by the enhanced convection electric field becomes $1-2 \mathrm{~km} / \mathrm{sec}$. According to the conclusion by Yeh and Foster (1990), the velocity is sufficient to cause the enhancements of the ion outflow in these regions due to frictional heating of ionospheric plasma. The detail discussion will be made in Section 4.4 in the present paper. On the other hand, the electric field data shown in the right panels of $\mathrm{E}$ to $\mathrm{H}$ in Fig. 5 show several important features of the large-scale electric field structure in the inner magnetosphere during the main phase of the magnetic storm. The remarkable point which characterizes the electric field distribution is an appearance of the strong dawnto-dusk electric field with the localized structure in the low $L$-value region of 1.9 to 4.0 . The averaged magnitude of the electric field was about $3.0-6.0 \mathrm{mV} / \mathrm{m}$ in this region. The peak magnitude gives about $7.4 \mathrm{mV} / \mathrm{m}$ to $16.5 \mathrm{mV} / \mathrm{m}$ located at the lower $L$-value region of 2.3-3.0. The structure of the electric field in the inner magnetosphere is maintained at least for the two orbital period, namely more than 3 hours. Therefore, this result indicates that the electric field structure does not present a temporal variation but a spatial feature. The second point of the electric field is that the 
electric field intensity in a lower $L$-value region of less than 6.0 is much larger than that in the higher latitude region of more than $L=6.0$. A typical example of the electric field feature is shown in the right panels $\mathrm{C}, \mathrm{F}$ and $\mathrm{H}$ of Figs. 4 and 5. The electric field intensity corresponds to the electric field drift speed of 1.2 to $4.6 \mathrm{~km} / \mathrm{sec}$ around $L=2.5$. In the case of the electric field distribution shown in the panel $\mathrm{F}$ in Fig. 5, if we assume that the structure of the electric field which affects all particles motion in the inner magnetosphere is maintained for 6 hours, the particles at $L=7.6$ will reach the inner plasmasphere at $L=2.1$ within less than 6 hours. The third point of the electric field is that the dusk-to-dawn electric field appears around $L=3.3$ and 4.4 in the inner magnetosphere in a narrow region of $\Delta L=0.51-0.62$, respectively as shown in the right panels of $F$ and $G$ in Fig. 5. The magnitude of the reversed convection electric field is about $3.2-6.2 \mathrm{mV} / \mathrm{m}$. The presence of the reversed convection electric field during the recovery phase of a magnetic storm is verified based on IS radar observation (Kelly, 1989) and the CRRES satellite observation near post-midnight sector (Wygant et al., 1998). However, the present study showed that the reversed convection electric field appears in the duskside inner magnetosphere during the main phase of the magnetic storm. Occurrence feature of the reversed convection electric field is different from that shown in the previous works. From the structure of the electric field, we can infer that there are several plasma vortices in the inner magnetosphere during the main phase of the magnetic storm. The generation mechanism of the plasma vortex should be solved in future study. On the other hand, although turbulent or bursty electric field perturbations appear within a region of $L<4.0$ with a large amplitude of 1.2 to $6.0 \mathrm{mV} / \mathrm{m}$ as shown in the panel $\mathrm{H}$ in Fig. 5, these phenomena seem to be an effect of large magnetic perturbations which occur in the inner magnetosphere during the main phase of the magnetic storm. The fourth point of the electric field structure is an abrupt decrease up to about $2.5-5.5 \mathrm{mV} / \mathrm{m}$ in the inner region of the location of the peak magnitude of the electric field as shown in the right panels $\mathrm{G}$ and $\mathrm{H}$ of Fig. 5. This electric field in this region is much larger than that in the period of a magnetically quiet condition. As reported by Wygant et al. (1998), this feature of the electric field distribution suggests a shielding effect of the electric field due to the injection of the hot plasma of the ring current in the inner magnetosphere and plasmasphere regions. To seek this shielding effect, we need to compare low energy particle within an energy range of 10 $\mathrm{eV}$ to $40 \mathrm{keV}$ and magnetic field data with the structure of the strong electric field. These studies should be done in future.

3.3.4 Recovery phase (I, J, K, L, M and N) In the left panels $\mathrm{I}-\mathrm{N}$ in Figs. 5 and 6 , the cold plasma density profiles are shown during the recovery phase of the magnetic storm. Although we can not identify the location of the plasmapause because of the data gap within an $L$-value range of 2.3-2.7 in the left panel I of Fig. 5, the plasmapause is located at about $L=2.48-3.39$ in a period of $\mathrm{J}$ to N. About 15 hours after the start of the recovery phase, in the panel $\mathrm{M}$, the plasmapause moves to the magnetosphere with a distance of $0.84 \mathrm{Re}$, compared with that in the right panel L of Fig. 6. This implies that the plasmasphere and the cold plasma density in this region recover up to the level of the quiet condition due to a decrease of the convection electric field in the magnetosphere. It is noted that the panels $\mathrm{K}$ and $\mathrm{L}$ indicate the existence of the plasma cavity region inside the plasmapause. From the fact that the same structure in this region is observed for the two orbital periods, namely, more than 3 hours, we can infer that the azimuthal width of this structure inside the plasmapause becomes about 45 degrees. It should be noted that the plasma trough region which disappears due to the enhancements of the plasma density in this region during the initial, main and early recovery phases of the magnetic storm appear outside the plasmapause again as shown in the left panels $M$ and $\mathrm{N}$. On the other hand, the electric field intensity shown in the right panels I-N of Figs. 5 and 6 gradually becomes weak in the inner magnetosphere within an $L$-value range of 2.0-5.0 as the SYM-H index and geomagnetic field of the H-component at Kakioka in Fig. 1 recover to the magnetically quiet level. The averaged magnitude of the electric field was about $0.7-2.4 \mathrm{mV} / \mathrm{m}$ in this region. As shown in the right panels $\mathrm{K}$ and $\mathrm{N}$ of Fig. 6, the strong electric field of the dawn-to-dusk component with the localized structure sometimes appears near the plasmapause during the recovery phase of the magnetic storm. The peak magnitude is about $5.5-11.4 \mathrm{mV} / \mathrm{m}$ at $L=2.9-3.1$ corresponding to the plasma drift velocity of $5.1-8.7 \mathrm{~km} / \mathrm{sec}$ at the point. In the late recovery phase of the magnetic storm, the electric field intensity in the outer region of $L>4.0$ as shown in the panels $\mathrm{M}$ and $\mathrm{N}$ of Fig. 6 is about 3-4 times larger that that in the inner region of $L<4.0$ except for an appearance of the strong electric field with the localized structure. This feature of the electric field distribution in the inner magnetosphere and plasmasphere regions during this period is opposite to that during the main phase. Therefore, this result implies that the electric field of the dawn-to-dusk component in the inner magnetosphere is almost diminished as the level of the pre-storm phase. However, it is noted, still in this case, the plasmasphere plasma has not been recovered yet to exactly co-rotate with the earth's rotation.

\section{Discussion}

4.1 Difference between storm-time strong electric field and rapid sub-auroral flows

Our present analysis results show that a strong dawn-todusk convection electric field with the localized structure appears in both the dawnside and duskside inner magnetosphere regions within an $L$-value range from 1.9 to 6.0 during the main phase of the super magnetic storm which occurred on March 13-15, 1989. The averaged magnitude of the electric field was about $3.0-6.0 \mathrm{mV} / \mathrm{m}$ in this region. The structure of the electric field in the inner magnetosphere is maintained at least for about 3 hours. From the $L$-value width where the intense electric field exists in this period, we can determine the maximum width of the magnetic latitude of appearance of the strong electric field at the ionosphere altitude as about $19.0^{\circ}$. The peak magnitude gives about $10.3 \mathrm{mV} / \mathrm{m}$ to $46.0 \mathrm{mV} / \mathrm{m}$ located at the lower $L$-value region of 2.3-3.3. The location of the peak magnitude of the electric field corresponds near the plasma- 
pause. Furthermore, our observation results also showed that the trough region and plasmapause disappear due to an enhancement of the plasma density in the auroral zone and polar cap region during the period when the strong convection electric field is observed during the main phase of the magnetic storm.

On the other hand, it has generally been known that there is a strong sub-auroral electric field with a localized structure both in space and time in subauroral region. The phenomena have been called the sub-auroral ion drift (SAID) (e.g., Galperin et al., 1975). The SAID phenomena have been noticed as important examples for studies of magnetosphere-ionosphere coupling for many workers and have dramatic effects on the ionosphere and thermosphere, including the formation of very deep density troughs in the F region (Spiro et al., 1978; Anderson et al., 1991), significant ionospheric compositional changes, very large fieldaligned vertical flows (Anderson et al., 1991), and significant latitudinally confined thermospheric winds (Anderson, 1996). The SAID phenomena are geomagnetic activity related, latitudinally narrow $\left(\sim 1^{\circ}-2^{\circ}\right)$ regions of rapid westward drift (sometimes exceeding $5 \mathrm{~km} / \mathrm{sec}$ in the ionosphere) located equatorward of the auroral oval, predominantly in the pre-midnight sector. Spiro et al. (1978) identified the SAID phenomena as the portion of sunward ionospheric flow equatorward of the auroral zone exceeding $500 \mathrm{~m} / \mathrm{sec}$, while Anderson et al. (1991) identified them as latitudinally confined regions of westward flow equatorward of the auroral oval exceeding $1000 \mathrm{~m} / \mathrm{sec}$. The subauroral flows correspond to the electric field intensity of $35-175 \mathrm{mV} / \mathrm{m}$ in the ionosphere at $L=4.0$. If we assume the equipotential along the magnetic field line in the inner magnetosphere, the electric field is mapped as a value of about $4.4-22 \mathrm{mV} / \mathrm{m}$ to the equatorial region. Anderson et al. (2001) reported that the magnetic latitude width of the occurrence region of the SAID phenomena observed by the DMSP and Akebono satellites is about $1^{\circ}-5^{\circ}$ below $L=4.0$. However, the present study suggests that the strong convection electric field which appears during the main phase of the magnetic storm is observed with a wide latitude range of $4.4^{\circ}-19.0^{\circ}$ in the inner magnetosphere. Our observation result shows that although the strong electric field intensity observed in the inner magnetosphere during the main phase of the magnetic storm is almost the same as that of the SAID phenomena, the occurrence region of the storm-time electric field is much wider than that of a typical case of the SAID phenomena.

Spiro et al. (1978) also showed that an occurrence probability of the SAID phenomena increases with increase of $K p$ value, while Anderson et al. (1993) and Karlsson et al. (1998) pointed out SAID occur almost exclusively during the substorm recovery phase. However, Burke et al. (2000) reported observations of the SAID phenomena appearing continuously during the ring current buildup associated with the main phase of a geomagnetic storm. Thus, the occurrence feature of the SAID phenomena for the magnetic activity has not yet been understood; however, the strong electric field observed in the present study has a clear dependence on the magnetic activity, which appears during each phase of the magnetic storm after the onset of SC.
Spiro et al. (1978) and Karlsson et al. (1998) suggested that the SAID phenomena are found predominantly between 18:00 and 02:00 MLT with the majority observed between 21:00 and 23:00 MLT. Karlsson et al. (1998) also showed that the peak occurrence probability of the SAID phenomena appears around 22:00 MLT. Anderson et al. (2001) concluded that the SAID phenomena simultaneously take place over a large magnetic local time range from at least 16:00 to 24:00 MLT. Although the previous section in this paper showed a feature of the storm-time electric field of the dawn-to-dusk component only in the dusk sector, the strong dawn-to-dusk convection electric field appears also in the dawn sector with the peak magnitude of about 4.2-9.7 $\mathrm{mV} / \mathrm{m}$ around $L=2.3-2.9$ of the low $L$-value region during the main phase of the magnetic storm which occurred on March 13-15, 1989. Therefore, the present analysis result suggests that the magnetic local time sector of occurrence region of the convection electric field observed by the Akebono satellite is different from that of the SAID phenomena which has been generally known.

From the above discussion, it is concluded that the strong large-scale convection electric field observed during the magnetic storm in the inner magnetosphere is distinguished from the SAID phenomena which appear equatorward of the auroral oval in the duskside sector. Furthermore, from the characteristics of the electric field with larger spatial scales which penetrates deeper into the plasmasphere and inner magnetosphere regions, the convection electric field is more likely to be able to inject ring current particles to low $L$-value regions.

Thus, the relation between the large-scale flows and rapid sub-auroral flows has not yet been clarified; however, Maynard et al. (1980) pointed out an example of an event characterized as a rapid sub-auroral flow which was not especially localized and which penetrated into $L=3.0$.

Some of the same physical processes which govern the structure of the SAID phenomena are likely to play an important role in creating and modifying the large-scale structure of the electric field, which include plasma sheet precipitation boundaries, regions of strong ionosphere conductivity, occurrence of strong shielding due to the hot plasma, and the presence of geomagnetic activity.

\subsection{Temporal variation of location and peak magni- tude of the localized electric field for development of the magnetic storm}

As has already mentioned in the Section 3, the present study showed that a strong dawn-to-dusk electric field appears in the inner magnetosphere and plasmasphere regions within an $L$-value range of 1.9-7.0 during the magnetic storm. The magnitude of the electric field distributes with a spatially inharmonious structure. Moreover, this distribution shows that the peaked electric field tends to appear with the localized feature in the low $L$-value region of less than 7.0. In this section, we discuss the time evolution of location and peak magnitude of the localized electric field for development of the magnetic storm. In Fig. 7, the SYM$\mathrm{H}$ index, the peak magnitudes and locations of the electric field of each satellite pass in the northern and southern hemispheres with time interval of about 1-3 hours are plotted within a period from March 12 to March 16, 1989. The 
peak magnitude of the electric field during the pre-storm phase prior to the onset of the first SC event at 01:26 (UT) on March 13 gives the low value range between 0.3 and 1.5 $\mathrm{mV} / \mathrm{m}$. The position of the peak magnitude is located at the relatively high $L$-value region of 3.6-6.7 as shown in the bottom panel of Fig. 7. After the magnetic storm began with the SC onset in the SYM-H index, the trend of the peak magnitude indicates an abrupt increase from $1.5 \mathrm{mV} / \mathrm{m}$ to $10.3 \mathrm{mV} / \mathrm{m}$ within the two orbital periods, namely, 6 hours, and the position of the peak magnitude also moves toward the earth with the distance of $3.5 \mathrm{Re}$ (from $L=6.4$ to $L=2.9$ ) in the same period. It is noted that the intense electric field also appears with almost the same magnitude in the next pass of the Akebono satellite. Moreover, the peak magnitude of the electric field is located at the lower $L$-value point $(L=2.4)$, compared with that in the previous orbit. Later, together with the development of the ring current during the main phase of the magnetic storm as shown in the

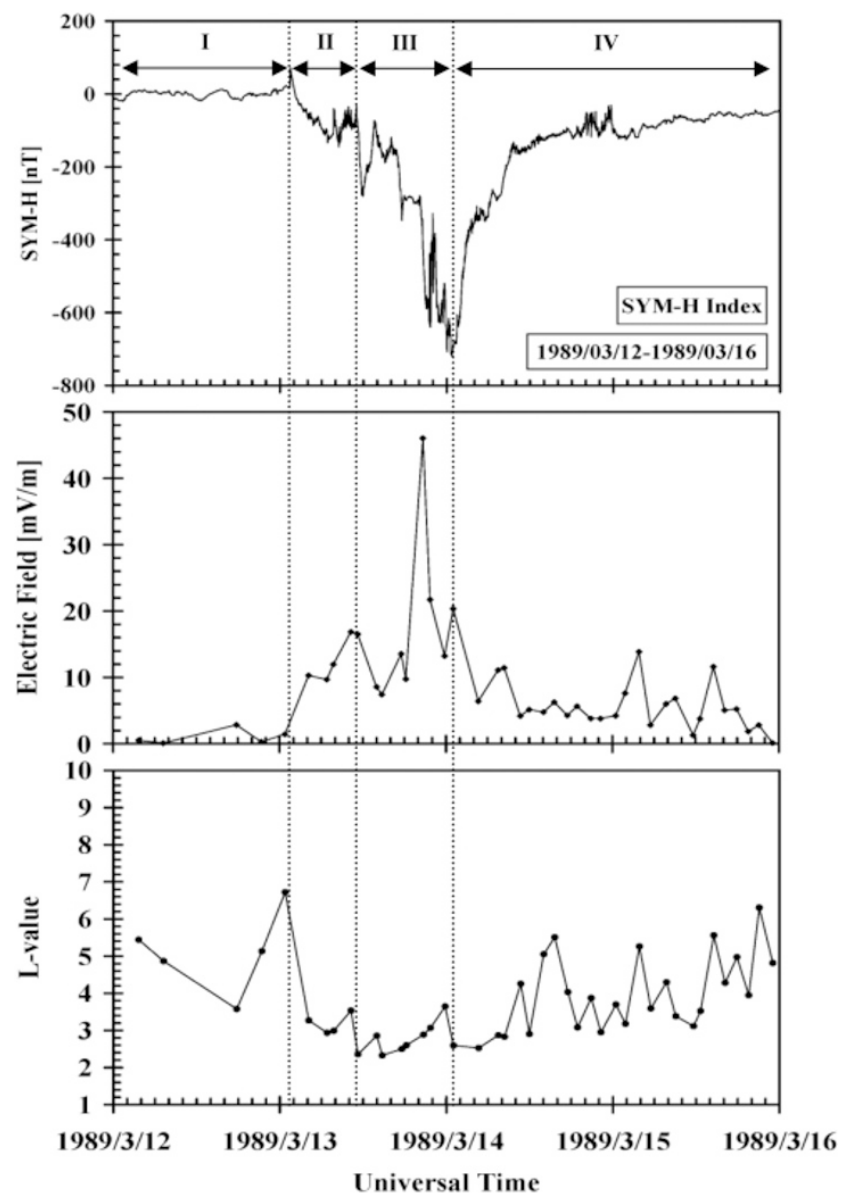

Fig. 7. Summary of the SYM-H index, the peak magnitude and location of the dawn-to-dusk electric field in the duskside inner magnetosphere during the magnetic storm. The horizontal arrows I, II, III, and IV in the upper panel present the pre-storm phase, initial phase, main and recovery phases of this storm, respectively. After the magnetic storm began with the onset of SC at 01:26 (UT) on March 13, 1989, the peak magnitude of the electric field is abruptly enhanced with several tens $\mathrm{mV} / \mathrm{m}$ during the development of the ring current. The position of the peak magnitude of the electric field shifts toward the earth with a distance of $3.5 \mathrm{Re}$. During the late recovery phase of the magnetic storm, the peak magnitude and position of the electric field recovers to the level of a magnetically quiet condition.
SYM-H index, the peak magnitude of the electric field gradually decrease from $16.9 \mathrm{mV} / \mathrm{m}$ to $7.4 \mathrm{mV} / \mathrm{m}$ although the magnitude increases from $9.8 \mathrm{mV} / \mathrm{m}$ to $46.0 \mathrm{mV} / \mathrm{m}$ again around the period when the SYM-H index gives the minimum value of $-720 \mathrm{nT}$. It is interesting that although the peak magnitude of the electric field varies to an extent of a factor mentioned above, its position is located at almost the same point in this period as shown in the bottom panel of Fig. 7. During the recovery phase of the magnetic storm, the peak magnitude of the electric field gradually decrease to the level of a magnetically quiet condition although the intense electric field suddenly appears in the low $L$-value region of less than 3.0 over several times. The position of the peak magnitude moves toward the more distant region from 3.0 to 5.0 during a late recovery phase after a half day of March 15.

Thus, it seems that the intense electric field directed in the dawn-to-dusk direction plays an important role in the injection of ring current ions deep into the magnetosphere and energization with its conversation of the first adiabatic invariant. A candidate of the generation mechanism of the localized and intense electric field in the inner magnetosphere is proposed by Southwood and Wolf (1978). They concluded that the intense poleward electric field at the ionosphere altitude takes place in the region between the inner edge of the plasma sheet ions and the low altitude edge of the electron precipitation when these edges are close to each other. This is due to the difference of the distribution of electrons and ions that the electric equipotential surfaces tend to be confined between the inner edge of the plasma sheet ions (earthward of which the electric field is shielded) and the region of the plasma sheet electrons (where the electric field is weakened due to the enhanced ionospheric conductivity). However, in the present study, we cannot determine the position of these edges from our observations since the low energy particle data obtained from the LEP instrument onboard the Akebono satellite are not available in the region of the invariant latitude of less than $60^{\circ}$. Therefore, in order to clarify the detail generation mechanism of the localized and intense electric field, the low energy particle observation of electrons and ions needs to be carried out in this region in future.

\subsection{Relationship between the localized electric field and the plasmapause}

From the present analysis of the simultaneous observation data of the electric field and the cold plasma density, it is found that the strong dawn-to-dusk electric field penetrates into the high density region $(>1000 / \mathrm{cc})$ within an $L$-value range of less than 3.0 with the large magnitude of about $2.0-12.0 \mathrm{mV} / \mathrm{m}$ during the magnetic storm. Although we could not identify the location of the plasmapause because of an enhancement of the cold plasma density in the trough region $(3.5<L<6.5)$ during the initial and main phases of the magnetic storm, Fig. 6 suggests that the peak magnitude of the electric field with the localized structure was located near the plasmapause during the recovery phase on March 14, 1989.

Figure 8 presents the locations of the peak magnitude of the electric field and of the plasmapause determined from the cold plasma density profile within a period from March 
12 to March 16, 1989. In Fig. 8, the trends of the locations of the plasmapause and of the peak magnitude of the electric field show almost the same feature for the magnetic activity in the inner magnetosphere. Both their locations are at the more distant region near $L=5.0$ during the pre-storm phase, while they shifted near $L=2.3-3.0$ toward the earth during the early recovery phase. It should be noted that the location of the plasmapause moves to the more distant region from $L=3.0$ to 5.3 within the period of less than 6 hours together with movement of the position of the peak magnitude of the electric field. Therefore, the relationship between the locations of the plasmapause and of the peak magnitude suggests that the intense electric field with the localized structure plays an important role on the formation of the plasmapause. The mechanism of the plasmapause formation was first explained by Nishida (1966), who proposed that the position of the plasmapause is defined between the convecting inner magnetospheric plasma (Axford and Hines, 1961) and the co-rotating plasmasphere. The theory was extended by Brice (1967), taking the discovery of the geomagnetic tail (Ness, 1965) into account. These proposals of the mechanism of the plasmapause formation have been intimately related to the refilling process of the flux tube of the magnetic field in the plasmasphere region, in addition to the sweeping out of plasma due to the magnetospheric convection with dependence on magnetic activity. Nishida's theory (1966) has been introduced by Singh and Horwitz (1992) as the concept that the plasmapause (in the steady state) corresponds to the boundary between flux tubes whose trajectories encircle the earth under the primary influence of the earth's co-rotation electric field and flux tubes further out whose trajectories are dominated by the magnetospheric convection electric field which intersect the dayside magnetopause. However, because the above classical theories of the plasmapause formation assume that the convection electric field distributes with a spatially homogeneous magnitude, their theories cannot describe the plasmapause revealed by the present study. It should take

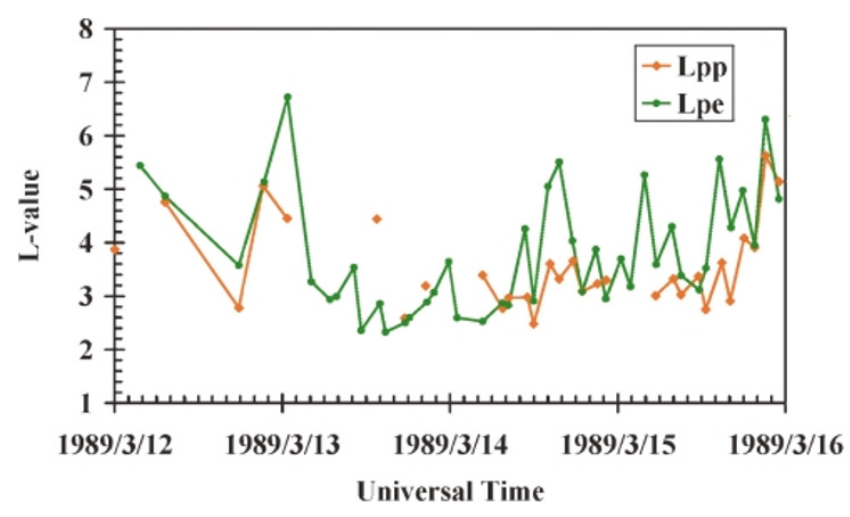

Fig. 8. Relationship between the locations of the plasmapause and of the peak magnitude of the electric field of the dawn-to-dusk component within a period from March 12 to March 16, 1989. The notations of "Lpe" and "Lpp" represent the locations of the plasmapause and of the peak magnitude of the electric field, respectively. The plasmapause is located near or outside the position of the peak magnitude of the electric field. The plasmapause during the late recovery phase of the magnetic storm is almost located at the position in a magnetically quiet condition. the spatially inhomogeneous convection electric field into account as shown in Section 3 in this paper.

\subsection{Enhancements of the cold plasma density from the trough region to auroral zone behavior}

From our data analysis of the cold plasma density in Section 3, the cold plasma density profile showed that the plasma density in the regions from the trough to auroral zone within an $L$-value range of 3.5-6.0 is abruptly enhanced with one or two order magnitude after the beginning of the magnetic storm, compared with that during a magnetically quiet period. This means that a mount of ionospheric cold plasma may be supplied into the trough region and auroral zone at the altitude of $2000 \mathrm{~km}$ to $6000 \mathrm{~km}$ in this period. While the enhancements of the cold plasma density are taking place in these regions, an intense dawnto-dusk electric field with the amplitude of 7.4-46.0 mV/m appears in the inner magnetosphere and plasmasphere regions within an $L$-value range of 1.9-7.0 during the magnetic storm. The magnitude of this electric field becomes about $26.7-244 \mathrm{mV} / \mathrm{m}$ when projected to the ionosphere altitude of the E-region, and this corresponds to the plasma drift speed of about $834 \mathrm{~m} / \mathrm{sec}$ to $7.6 \mathrm{~km} / \mathrm{sec}$. Based on the Millstone Hill $\left(42.6^{\circ} \mathrm{N}, 71.5^{\circ} \mathrm{W}\right)$ mid-latitude ionospheric radar observations, Yeh et al. (1991) also found that a strong convection electric field exists in the duskside ionosphere between $L=2$ and $L=4$ during the main phase of an intense magnetic storm with the Dst minimum value of about -320 nT which occurred on February 8, 1986. The peak value of the electric field was about $30-40 \mathrm{mV} / \mathrm{m}$ at $L=2.4-3.0$.

Growing experimental evidence and theoretical investigations suggests that heavy ion outflow can be found in many regions of the magnetosphere-ionosphere system during a magnetically active condition. Satellite observations of ion outflow at high altitudes $(>5000 \mathrm{~km})$ have been extensively studied in many previous works (e.g., Shelley et al., 1976; Lockwood et al., 1985; Waite et al., 1985; Yau et al., 1985; Chappell et al., 1987). Lockwood et al. (1985) showed that occurrence of the heavy ion outflow depends on $K p$ index by using the retarding ion mass spectrometer (RIMS) data obtained from the DE-1 satellite for 2 years. In explaining the generation of heavy ion outflows in the topside auroral ionosphere, most mechanisms relate its cause to plasma heating driven by the combined effects of the convection electric field, particle precipitation, and the ionosphere-thermosphere interaction. Rapid ion frictional heating (St.-Maurice and Schunk, 1979) was most commonly suggested as the principal driver for the field-aligned ion outflows observed in the dayside convection throat and nightside auroral zone and polar cap boundary (e.g., Gombosi and Killeen, 1987). Perpendicular ion heating which resulted from either nonthermal plasma effects (Lockwood and Fuller-Rowell, 1987) or ion cyclotron acceleration driven by downward field-aligned currents (Lockwood, 1982), and the subsequent enhanced magnetic mirror effect, can also contribute significantly to the formation of heavy ion outflows (Suvanto et al., 1989). In addition to frictional ion heating, the transient response of the topside ionosphere to the soft electron $(\sim 100 \mathrm{eV})$ precipitation (Whitteker, 1977), enhanced electron heating 
(Barakat and Schunk, 1983), and the temporal evolution of field-aligned current (Gombosi and Nagy, 1989) have also been proposed as the cause of tranjent heavy ion outflows. Yeh and Foster (1990) reported that ion temperatures in excess of $4000 \mathrm{~K}$ at $500 \mathrm{~km}$ altitude, which indicate a good correlation with fast ion velocity of more than $500 \mathrm{~km} / \mathrm{sec}$, are observed by the ionospheric radar in the vicinity of the ion outflow event at $L=3.0$ during the major magnetic storm on February 8, 1986. From comparison with the satellite observation, Yeh and Foster (1990) also mentioned that the outflow event can be explained in terms of a timedependent diffusion process triggered by a sudden change in the frictional heating rate in the collision-dominated Fregion, and concluded that the mid-latitude ionosphere constitutes a significant source of upflowing thermal O+ fluxes to the overlying magnetosphere. In recent study on the response of the mid-latitude ionosphere during the major magnetic storm, Goncharenko et al. (2004) found the existence of a strong convection electric field with the magnitude of about $30-120 \mathrm{mV} / \mathrm{m}$ in both the dawnside and duskside ionospheric E regions $(100-150 \mathrm{~km})$ at mid-latitudes during several intense magnetic storms $(K p=8-9)$ by using the incoherent scatter radar at Millstone Hill. Their observation results revealed $\mathrm{E}$ region zonal plasma drifts of $300-1000 \mathrm{~m} / \mathrm{sec}$, westward in the evening sector and eastward in the morning sector which correspond to the ionospheric convection pattern. Goncharenko et al. (2004) showed that the tidal pattern of neutral winds in the lower thermosphere is heavily disrupted and that the zonal component of the neutral wind follows convection-driven ion flow. Therefore, from the above ionospheric observation results, the enhancements of the cold plasma density in the regions of the trough and auroral zone of $L=3.5-6.0$ observed by the Akebono satellite can be explained by supply of the ionospheric plasma to the inner magnetosphere and plasmasphere regions due to the ion upflowing, which is generated by the frictional ion heating in the ionosphere.

\section{Conclusion}

Evolution of the cold plasma density distribution and large-scale electric field variations in the inner magnetosphere and plasmasphere regions during the super geomagnetic storm which occurred on March 13-15, 1989 were investigated by using the observation data of the Akebono satellite which has been carried out for more than 15 yeas since March, 1989. The major results obtained from this data set are summarized as follows:

1. During the pre-storm phase, the electric field data show a spatially homogeneous distribution with a small magnitude of about $0.1-0.3 \mathrm{mV} / \mathrm{m}$ in the inner magnetosphere within an $L$-value range from 2.2 to 10.0. From comparison between the electric field and the cold plasma density structure obtained from the upper cutoff frequency of the UHR waves, the signature of the electric field suggests that the convection electric field penetrates into the inner plasmasphere around $L=2.2$ under any magnetically quiet condition. The magnitude of the electric field does not show a clear change near the plasmapause at $L=5.1$ in the case of the left panel A of Fig. 4. This evidence implies that the plasmaspheric plasma moves with a co-rotation lag from the earth's rotation.

2. The response of the convection electric field during an SC showed that after the initial excursion of the electric field for about 2 minute due to the passage of fast-mode waves associated with SC, the electric field with the averaged magnitude of about $3.4 \mathrm{mV} / \mathrm{m}$ is enhanced in the inner magnetosphere and plasmasphere region of the dawnside and duskside sectors. The enhanced convection electric field penetrates deep into the inner magnetosphere region at $L=3.0-6.4$. It has been widely accepted that the electric field plays an important role in creating the main impulse (MI) of SC disturbances (e.g., Araki, 1994).

3. During the initial and main phases of the magnetic storm, the convection electric field is enhanced with a complex structure in the inner magnetosphere within an $L$-value range from 1.9 to 7.0. An important feature of the electric field intensity in the inner magnetosphere is that the magnitude is much stronger earthward of $L=1.9-6.0$ than at positions more distant than $L=7.0$. The averaged magnitude of the electric field was about $3.0-6.0 \mathrm{mV} / \mathrm{m}$ in this region. The peak magnitude gave about $7.4 \mathrm{mV} / \mathrm{m}$ to 46.0 $\mathrm{mV} / \mathrm{m}$ located at the lower $L$-value region of 2.3-3.3 near the plasmapause. These magnitudes were much larger than quiet time values of the electric field by a factor of 30 or more. These electric field were capable of injecting ring current particles from $L=8.0$ to $L=2.3$ and energizing the plasma sheet particles through the conservation of the first adiabatic invariance. The localized structure of the dawn-to-dusk electric field in the inner magnetosphere is maintained at least for the two orbital period, namely more than 3 hours. On the other hand, the cold plasma density data showed that the plasma density near the trough region around $L=3.0-6.0$ was enhanced with one or two order magnitude associated with an appearance of the strong convection electric field, compared with that in the magnetically quiet condition. This implies that a mount of the ionospheric plasma may be supplied from the topside ionosphere into the trough and plasmasphere regions by the frictional heating due to the fast plasma convection in the ionosphere as reported by Yeh and Foster (1990)

4. The electric field intensity during the recovery phase of the magnetic storm gradually weakens in the inner magnetosphere within an $L$-value range of 2.0-5.0 as the SYM$\mathrm{H}$ index and geomagnetic field of the H-component at Kakioka in Fig. 1 recover to the magnetically quiet level. The averaged magnitude of the electric field was about $0.7-$ $2.4 \mathrm{mV} / \mathrm{m}$ in this region. The strong electric field of the dawn-to-dusk component with the localized structure with the peak magnitude of about $5.6-11.3 \mathrm{mV} / \mathrm{m}$ sometimes appears near the plasmapause in this period. In the late recovery phase of the magnetic storm, the electric field intensity in the outer region of $L>4.0$ is about 3-4 times larger that that in the inner region of $L<4.0$ except for an appearance of the strong electric field with the localized structure. This feature of the electric field distribution in the inner magnetosphere and plasmasphere regions during this period is opposite to that during the main phase.

Acknowledgments. The Akebono satellite was established by the Institute of Space and Astronautical Science (ISAS). Authors used 
magnetic field data at Kakioka Magnetic Observatory and geomagnetic indices obtained from WDC-C2 in Kyoto University. Interplanetary magnetic field data are provided by NASA Goddard Space Flight Center. Activities of three authors (T. Ono, M. Iizima, and A. Kumamoto) are supported by the 21 st century COE program "Advanced Science and Technology Center for the Dynamic Earth" at Tohoku University. The author (A. Shinbori) is also supported by a grant of Research Fellowship of the Japan Society for the Promotion of Science for Young Scientists.

\section{References}

Anderson, P. C., Subauroral ion drifts (SAID): Previous results and present studies, in Proceedings of the 1995 Cambridge Symposium/Workshop in Geoplasma Physics on "Multiscale Phenomena in Space Plasmas", edited by T. Chang, and J. R. Jasperse, pp. 15, Mass. Inst. of Technol. Cent. for Space Res., Cambridge, 1996.

Anderson, P. C., W. B. Hanson, and R. A. Heelis, The ionospheric signatures of rapid subauroral ion drifts, J. Geophys. Res., 96, 5785-5792, 1991.

Anderson, P. C., W. B. Hanson, R. A. Heelis, J. D. Craven, D. N. Baker, and L. A. Frank, A proposed production model of rapid subauroral ion drifts and their relationship to substorm evolution, J. Geophys. Res., 98, 6069-6078, 1993.

Anderson, P. C., D. L. Carpenter, K. Tsuruda, T. Mukai, and F. J. Rich, Multisatellite observations of rapid subauroral ion drift (SAID), J. Geophys. Res., 106, 29585-29599, 2001

Araki, T., A physical model of the geomagnetic sudden commencement, in Solar Wind Sources of Magnetospheric Ultra-Low-Frequency Waves, Geophys. Monogr. Ser., vol. 81, edited by M. J. Engebretson, K. Takahashi, and M. Scholer, pp. 183-200, AGU, Washington, D. C., 1994.

Axford, W. I., Magnetospheric convection, Rev. Geophys. Space Phys., 7, 421-459, 1969.

Axford, W. I. and C. O. Hines, A unifying theory of high-latitude geophysical phenomena and geomagnetic storms, Can. J. Phys., 39, 1433-1464, 1961.

Barakat, A. R. and R. W. Schunk, $\mathrm{O}^{+}$ions in the polar wind, J. Geophys. Res., 88, 7887-7894, 1983.

Baumjohann, W. and G. Haerendel, Magnetospheric convection observed between 0600 and 2100 LT: Solar wind and IMF dependence, J. Geophys. Res., 90, 6370-6378, 1985.

Baumjouhann, W., G. Haerendel, and F. Melzner, Magnetospheric convection observed between 0600 and $2100 \mathrm{LT}$ : Variations with Kp, J. Geophys. Res., 90, 393-398, 1985.

Blake, J. B., W. A. Kolasinski, R. W. Fillius, and E. G. Mullen, Injection of electrons and protons with energies of tens of $\mathrm{MeV}$ into $L<3$ on March 24, 1991, Geophys. Res. Lett., 19, 821-824, 1992.

Brice, N. M., Bulk motion of the magnetosphere, J. Geophys. Res., 72, 5193-5211, 1967

Burke, W. J., A. G. Rubin, N. C. Maynard, L. C. Gentile, P. J. Sultan, F. J. Rich, O. de La Beaujardiere, C. Y. Huang, and G. R. Wilson, Ionospheric disturbances observed by DMSP at middle to low latitudes during the magnetic storm of June 4-6, 1991, J. Geophys. Res., 105, 18391-18405, 2000.

Cahill, L. J., N. G. Waite, M. J. Engebretson, and M. Sugiura, Toroidal standing waves excited by a storm sudden commencement: DE1 observations, J. Geophys. Res., 95, 7857-7867, 1990.

Carpenter, D. L., Whistler studies of the plasmapause in the magnetosphere, I. Temporal variations in the position of the knee and some evidence on plasma motions near the knee, J. Geophys. Res., 71, 693-709, 1966.

Carpenter, D. L. and R. R. Anderson, An ISEE/whistler model of equatorial electron density in the magnetosphere, J. Geophys. Res., 97, 1097$1108,1992$.

Chappell, C. R., T. E. Moore, and J. H. Waite, Jr., The ionosphere as a fully adequate source of plasma for the Earth's magnetosphere, J. Geophys. Res., 92, 5896-5910, 1987.

Clauer, C. R. and Y. Kamide, DP1 and DP2 current systems for the March 22, 1979, substorms, J. Geophys. Res., 90, 1343-1354, 1985.

Daglis, I. A., R. M. Thorne, W. Baumjohann, and S. Orsini, The terrestrial ring current: Origin, formation and decay, Rev. Geophys., 37, 407-438, 1999.

Dungey, J. W., Interplanetary magnetic field and the auroral zones, Phys. Rev. Lett., 6, 47-48, 1961.

Dungey, J. W., The structure of the exosphere, or Adventures in velocity space, in Geophysics, The Earth's Environment, edited by C. DeWitt, J.
Hieblot, and A. Lebeau, pp. 526-537, Gordon and Breach New York, 1963.

Foster, J. C., A. J. Coster, P. J. Erickson, F. J. Rich, and B. R. Sandel, Stormtime observations of the flux of plasmaspheric ions to the dayside cusp/magnetopause, Geophys. Res. Lett., 31, L08809, doi:10.1029/2004GL020082, 2004.

Galperin, Yu. I., V. N. Ponomarev, Yu. N. Ponomarev, and A. G. Zosimova, Plasma convection in the evning sector of the magnetosphere and the nature of the plasmapause, Kosmicheskie Issledovanya, 18, 669-686, 1975

Gombosi, T. I. and T. L. Killeen, Effects of thermospheric motions on the polar wind: A time-dependent numerical study, J. Geophys. Res., 92 4725-4729, 1987.

Gombosi, T. I. and A. F. Nagy, Time-dependent modeling of field-aligned current-generated ion transients in the polar wind, J. Geophys. Res., 94, 359-369, 1989.

Goncharenko, L. P., J. E. Salah, J. C. Foster, and C. Huang, Variations in lower thermosphere dynamics at midlatitudes during intense geomagnetic storms, J. Geophys. Res., 109, A04304, doi:10.1029/2003JA010244, 2004

Hayakawa, H., T. Okada, M. Ejiri, A. Kadokura, Y.-I. Kohno, K. Maezawa, S. Machida, A. Matsuoka, T. Mukai, M. Nakamura, A. Nishida, T. Obara, Y. Tanaka, F. S. Mozer, G. Haerendel, and K. Tsuruta, Electric field measurement on the Akebono (EXOS-D) satellite, J. Geomag. Geoelectr., 42, 371-385, 1990.

Heelis, R. A., R. A. Spiro, W. B. Hanson, and J. L. Burch, Magnetosphere ionosphere coupling in the mid-latitude trough, Eos Trans. AGU, 57, 990, 1976.

Iyemori, T. and D. R. K. Rao, Decay of the Dst field of geomagnetic disturbance after substorm onset and its implication to storm-substorm relation, Ann. Geophys., 14, 608-618, 1996.

Karlsson, T., G. T. Marklund, and L. G. Blomberg, Subauroral electric fields observed by the Freja satellite: A statistical study, J. Geophys. Res., 103, 4327-4341, 1998.

Kelly, M., The Earth's Ionosphere, Academic, San Diego, Calif., 1989.

Knott, K., A. Pedersen, and U. Wedeken, GEOS 2 electric field observation during a sudden commencement and subsequent substorm, J. Geophys. Res., 90, 1283-1288, 1985.

Laakso, H. and R. Schmidt, Pc 4-5 pulsation in the electric field at geostationary orbit (GEOS2) triggered by sudden commencements, J. Geophys. Res., 94, 6626-6632, 1989.

Levy, R. H., H. E. Petschek, and G. I. Siscoe, Aerodynamics aspects of magnetospheric flow, AIAA J., 2, 2065-2076, 1964.

Li, X., I. Roth, M. Temerin, J. Wygant, M. K. Hudson, and J. B. Blake, Simulation of the prompt energization and transport of radiation particles during the March 24, 1991 SSC, Geophys. Res. Lett., 20, 2423 2426, 1993.

Lockwood, M., Thermal ion flows in the topside auroral ionosphere and the effects of low-altitude transverse acceleration, Planet. Space Sci. 30, 595-609, 1982.

Lockwood, M. and T. J. Fuller-Rowell, The modeled occurrence of nonthermal plasma in the ionospheric $\mathrm{F}$ region and the possible consequences for ion outflows into the magnetosphere, Geophys. Res. Lett., 14, 371-374, 1987.

Lockwood, M., J. H. Waite, Jr., T. E. Moore, J. F. E. Johnson, and C. R. Chappell, A new source of suprathermal $\mathrm{O}^{+}$ions near the dayside polar cap boundary, J. Geophys. Res., 90, 4099-4116, 1985.

Maynard, N. C. and A. J. Chen, Isolated cold plasma regions: Observations and their relation to possible production mechanisms, J. Geophys. Res., 80, 1009-1013, 1975.

Maynard, N. C., T. L. Aggson, and J. P. Heppner, Magnetospheric observation of large sub-auroral electric fields, Geophys. Res. Lett., 7, 881-884, 1980

Maynard, N. C., T. L. Aggson, and J. P. Heppner, The plasmaspheric electric field as measured by ISEE 1, J. Geophys. Res., 88, 3981-3990, 1983.

Mozer, F. S., Electric field mapping in the ionosphere at the equatorial plane, Planet Space Sci., 18, 259-263, 1970.

Ness, N. F., The earth's magnetic tail, J. Geophys. Res., 70, 2989-3005, 1965.

Nishida, A., Formation of plasmapause, or magnetospheric plasma knee by combined action of magnetospheric convection and plasma escape from the tail, J. Geophys. Res., 71, 5669-5679, 1966.

Nishida, A., Coherence of geomagnetic DP-2 fluctuations with interplanetary magnetic variations, J. Geophys. Res., 73, 5549-5559, 1968.

Okada, T., H. Hayakawa, K. Tsuruda, A. Nishida, and A. Matsuoka, EXOS 
D observations of enhanced electric fields during the giant magnetic storm in March 1989, J. Geophys. Res., 98, 15417-15424, 1993.

Oya, H., Studies on plasma and plasma waves in the plasmasphere and auroral particle acceleration region, by PWS on board the EXOS-D (Akebono) satellite, J. Geomag. Geoelectr., 43, Suppl., 369-393, 1991.

Oya, H., Dynamical variation of plasmasphere revealed by PWS data onboard the Akebono (EXOS-D) satellite, J. Geomag. Geoelectr., 49, Suppl., 159-178, 1997.

Oya, H., Effect of betatron drift on plasmasphere and plasmapause verified by the Akebono (EXOS-D) satellite observations, in Advances in Solar-Terrestrial Physics, edited by H. Oya, pp. 145-174, TERRAPUB, Tokyo, 2004.

Oya, H., A. Morioka, K. Kobayashi, M. Iizima, T. Ono, H. Miyaoka, T. Okada, and T. Obara, Plasma wave observation and sounder experiments (PWS) using the Akebono (EXOS-D) satellite-instrumentation and initial results including discovery of the high altitude equatorial plasma turbulence, J. Geomag. Geoelectr., 42, 411-422, 1990.

Rowland, D. E. and J. R. Wygant, Dependence of the large-scale, inner magnetospheric electric field on geomagnetic activity, J. Geophys. Res., 103, 14959-14964, 1998.

Shelley, E. G., R. D. Sharp, and R. G. Johnson, Satellite observations of an ionospheric acceleration mechanism, Geophys. Res. Lett., 3, 654-567, 1976.

Shinbori, A., T. Ono, M. Iizima, A. Kumamoto, and H. Oya, Sudden commencements related plasma waves observed by the Akebono satellite in the polar region and inside the plasmasphere region, J. Geophys. Res., 108, 1457, doi:10.1029/2003JA009964, 2003.

Shinbori, A., T. Ono, M. Iizima, and A. Kumamoto, SC related electric and magnetic field phenomena observed by the Akebono satellite inside the plasmasphere, Earth Planets Space, 56, 269-282, 2004a.

Shinbori, A., T. Ono, M. Iizima, A. Kumamoto and Y. Nishimura, Enhancements of magnetospheric convection electric field associated with sudden commencements in the inner magnetosphere and plasmasphere regions, Adv. Space Res., $2004 \mathrm{~b}$ (in press).

Singh, N. and J. L. Horwitz, Plasmasphere refilling: recent observations and modeling, J. Geophys. Res., 97, 1049-1079, 1992.

Sojka, J. J., C. E. Rasmussen, and R. W. Schunk, An interplanetary magnetic field dependent model of the ionospheric convection electric field, J. Geophys. Res., 91, 11281-11290, 1986.

Southwood, D. J. and R. A. Wolf, An assessment of the role of precipitation in magnetospheric convection, J. Geophys. Res., 83, 5227-5232, 1978.

Spiro, R. W., R. A. Heelis, and W. B. Hanson, Rapid subauroral ion drifts observed by Atmosphere Explore C, Geophys. Res. Lett., 8, 657-660, 1978.

Spiro, R. W., R. A. Heelis, and W. B. Hanson, Ion convection and the formation of the midlatitude $\mathrm{F}$ region ionization trough, J. Geophys. Res., 83, 4255-64, 1978.

St.-Maurice, J.-P. and R. W. Schunk, Ion velocity distribution in the auroral ionosphere, Rev. Geophys. Space Phys., 17, 99-134, 1979.

Stern, D. P., A study of the electric field in an open magnetospheric model, J. Geophys. Res., 78, 7292-7305, 1973.

Stern, D. P., Large-scale electric field in the earth's magnetosphere, $R e$ views of Geophys and Space Phys., 15, 156-194, 1977.

Suvanto, K., M. Lockwood, and T. J. Fuller-Rowell, The influence of anisotropic $\mathrm{F}$ region ion velocity distributions on ionospheric ion outflows into the magnetosphere, J. Geophys. Res., 94, 1347-1358, 1989.

Volland, H., A semiemperical model of large-scale magnetospheric electric fields, J. Geophys. Res., 78, 171-180, 1973.

Waite, J. H., Jr., T. Nagai, J. F. E. Johnson, C. R. Chapell, J. L. Burch, T. L. Killeen, P. B. Hayyes, G. R. Carignan, W. K. Peterson, and E. G. Shelley, Escape of suprathermal $\mathrm{O}^{+}$ions in the polar cap, J. Geophys. Res., 90, 1619-1630, 1985.

Whitteker, J. H., The transient response of the topside ionosphere to precipitation, Planet. Space Sci., 25, 773-786, 1977.

Wilson, G. R., W. J. Burke, N. C. Maynard, C. Y. Huang, and H. J. Singer, Global electrodynamics observed during the initial and main phase of the July 1991 magnetic storm, J. Geophys. Res., 106, 24517-24539, 2001.

Wygant, J., F. Mozer, M. Temerin, J. Blake, N. Maynard, H. Singer, and M. Smiddy, Large amplitude electric field and magnetic field signatures in the inner magnetosphere during injection of $15 \mathrm{MeV}$ electron drift echoes, Geophys. Res. Lett., 21, 1739-1742, 1994.

Wygant, J., D. Rowland, H. J. Singer, M. Temerin, F. Mozer, and M. K. Hudson, Experimental evidence on the role of the large spatial scale electric field in creating the ring current, J. Geophys. Res., 103, 29527$29544,1998$.

Yau, A. W., E. G. Shelley, W. K. Peterson, and L. Lenchyshyn, Energetic auroral and polar ion outflow at DE-1 altitudes: Magnitude, composition, magnetic activity dependence, and long-term variations, J. Geophys. Res., 90, 8417-8432, 1985.

Yeh, H.-C. and J. C. Foster, Storm time heavy ion outflow at mid-latitude, J. Geophys. Res., 95, 7881-7891, 1990.

Yeh, H.-C., J. C. Foster, F. J. Rich, and W. Swider, Storm time electric field penetration observed at mid-latitude, J. Geophys. Res., 96, 5707-5721, 1991.

A. Shinbori (e-mail: atsuki@stpp1.geophys.tohoku.ac.jp), Y. Nishimura, T. Ono, M. Iizima, A. Kumamoto, and H. Oya 